\title{
5. Biomass Transformation into Chemicals Using Zeolites and MOFs
}

\author{
Óscar Hernando Laguna Espita, ${ }^{1}$ Simona M. Coman, ${ }^{2}$ \\ Miguel Ángel Centeno Gallego ${ }^{1}$ and Vasile I. Pârvulescu ${ }^{2}$ \\ ${ }^{1}$ Institute of Materials Science of Seville, CSIC-University of \\ Seville, Américo Vespucio 49, 41092 Seville, Spain.
}

${ }^{2}$ Department of Organic Chemistry, Biochemistry and Catalysis, Faculty of Chemistry, University of Bucharest, 4-12 Regina Elisabeta Av., Bucharest, Romania.

Keywords: Cellulose, lignin, biorefinery, platform molecule

\section{Introduction}

Biomass is referred to as a renewable source of materials and energy, which it is most often associated with plants or plant-based materials that are not used for food or as a feed. From a chemical point of view, interest is focused on the valorization of the dry matter of biomass, commonly known as lignocellulosic biomass. Its total annual production exceeds 100,000 million tons of carbon, which corresponds to an associated energy of $1.5 \times 10^{3}$

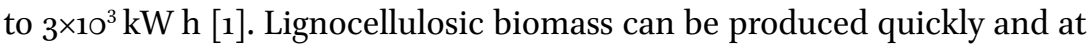
a low cost and is significantly cheaper than crude oil, generating both important economic and environmental advantages [2].

Lignocellulosic biomass is a tridimensional structure mainly composed of three polymers: cellulose, hemicellulose and lignin, together with small amounts of other components, like acetyl groups, minerals and phenolic substituents (Figure 1). Cellulose represents the main crystalline component of lignocellulosic biomass, whichisformed by repeating units of the disaccharide cellobiose. The second most abundant polymer is hemicellulose, which presents an amorphous structure composed of several heteropolymers, including xylan, galactomannan, glucuronoxylan, arabinoxylan, glucomannan, and xyloglucan. Lignin is the third main component, with a three dimensional structure of phenylpropanoid units including $p$-coumaryl alcohol, coniferyl alcohol, and sinapyl alcohol. 


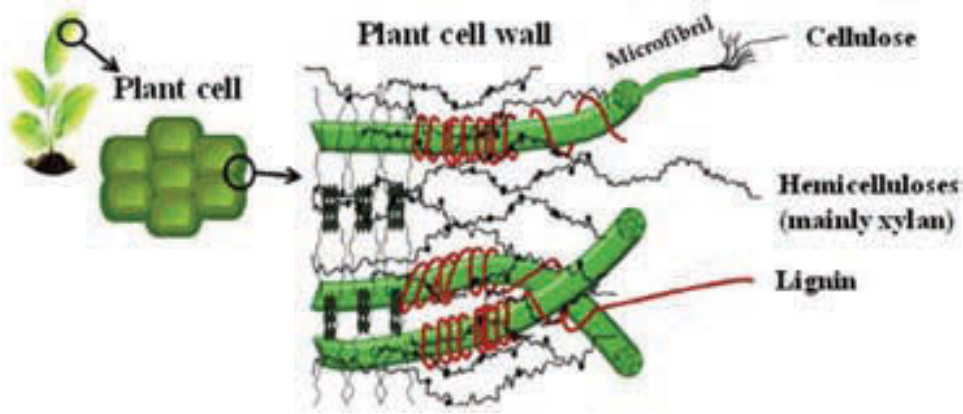

Figure 1. Lignocellulosic biomass generation and composition. By Khanok Ratanakhanokchai, Rattiya Waeonukul, Patthra Pason, Chakrit Tachaapaikoon, Khin Lay Kyu, Kazuo Sakka, Akihiko Kosugi and Yutaka Mori. CC BY-SA 3.0. DOI: 10.5772/51820.

All three components of lignocellulosic biomass have a large quantity of oxygen: almost half for cellulose, $\left(\mathrm{C}_{6} \mathrm{H}_{10} \mathrm{O}_{5}\right)_{\mathrm{n}}$, and around $30 \%$ for lignin, $\left(\mathrm{C}_{9} \mathrm{H}_{10} \mathrm{O}_{2}\right)_{\mathrm{n}}$. Nowadays, most feedstocks for the manufacture of commodity chemicals and polymers are obtained from fossil oil [3]. To produce them, an intermediate selective oxidation step is required in many cases. However, this step often has a low environmental (E-) factor and generates $\mathrm{CO}_{2}$, contributing to an increase in the greenhouse effect. Therefore, it appears wiser to valorize the oxygen already present in the lignocellulosic biomass for the production of commodity chemicals and polymers, and to devote fossil oil to the production of deoxygenated products.

The main step in chemical valorization of lignocellulosic resources involves, the depolymerization of the macromolecules. While for cellulose an efficient hydrolysis can directly generate monomers, lignin fragmentation is more difficult since the polymers are formed by connecting aromatic entities via both etheric and C-C bonds. Thus, the hydrolysis of cellulose is easier and has been reported by enzymatic [4-6], homogeneous [7] or heterogeneous catalysis [8]. The more complex fragmentation of lignin was carried using multiple approaches like fast pyrolysis $[9,10]$ or homogeneous and heterogeneous catalysis [11] followed by extraction [12]. In this case, the result is a cocktail of small aromatic molecules with different functionalities and masses. Figure 2 depicts the fragmentation of cellulose, along with further chemical valorization.

The solvent is very important in the chemical valorization of biomass. To date, achievements in conversion processes in both water and organic solvents have been reported, including the conversion of biomass to sugars, the conversion of sugars to furanic compounds, and the production of lignin monomers [13]. The solvent influences both conversion and product selectivity as it can affect the solubility of the biomass components, including 


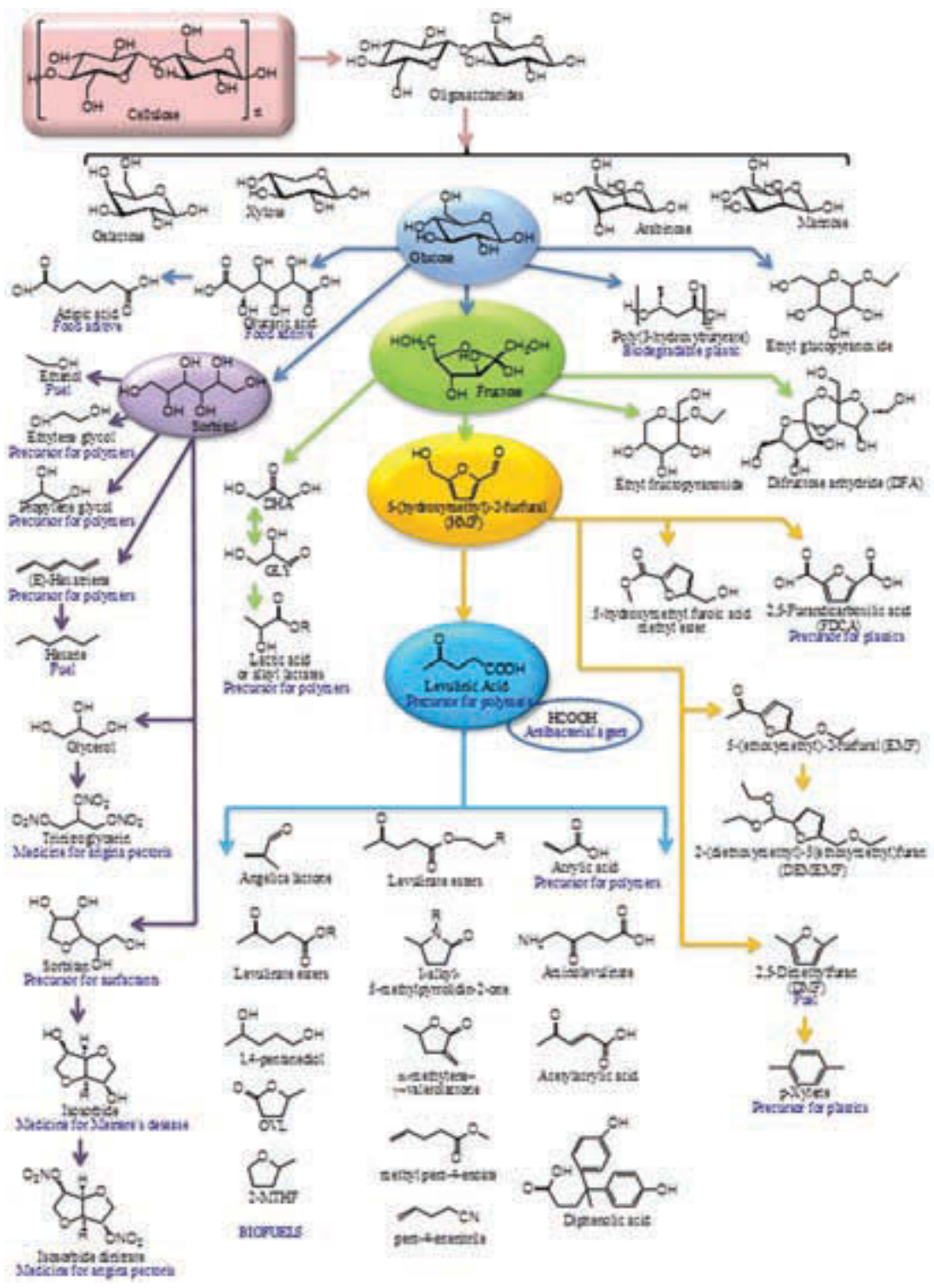

Figure 2. Fragmentation of cellulose and further transformations.

cellulose and lignin, and also affect the thermodynamics of reactants, intermediates, products, and/or catalysts. Studies carried in sub- and supercritical water revealed the advantages of working under supercritical conditions [14].

Overall, the aim of this chapter is to discuss the use of zeolites and metal-organic frameworks (MOFs) as catalysts for the fragmentation of cellulose and lignin and for the valorization of the resulting monomers 
by producing valuable chemicals. This approach is closely related to the concept of sustainability [15]. Both zeolites and MOFs present similar properties which make them perfect candidates for their application in these types of reactions, such as shape selectivity, microporosity, the simultaneous presence of Brønsted and Lewis acid sites, metallic active sites, and related crystal structures, which have been discussed in previous chapters. However, important differences exist between both families of materials in terms of diffusion, adsorption and stability aspects. Besides this, MOFs present a structural versatility that allows the tailored design of a huge variety of different MOF structures, exceeding the number of zeolite structures available. On top of this, zeolites are well-known materials applied since the 196 os in different catalytic processes, while MOFs chemistry is just beginning and only a few families of materials have been employed so far. Thus, our chapter will describe firstly the use of zeolites in the main types of reactions for biomass transformation and, in the second part, the differences between and opportunities for using MOFs.

\section{Cellulose transformation into chemicals using zeolites}

The fragmentation of cellulose and hemicellulose carbohydrate polymers into their $\mathrm{C}_{5}$ and $\mathrm{C}_{6}$ constituent sugars and their subsequent transformation into biorefinery platform molecules for chemical commodities represents a unique means for the production of various oxygenates, such as furfural, 5-hydroxymethylfurfural, xylitol, sorbitol, mannitol, gluconic acid, etc. [16] The use of zeolites as market-accessible solid acid catalysts offers big opportunities.

Zeolites are microporous minerals commonly used as catalysts for acid catalysed reactions. They are also known as 'molecular sieves', mainly consisting of $\mathrm{Si}, \mathrm{Al}$ and $\mathrm{O}$, although the replacement of cations by metals such as $\mathrm{Ti}, \mathrm{Sn}$ or $\mathrm{Zn}$ is also possible. The concomitant presence of two cations in different oxidation states in the structure of these materials requires the compensation by a proton, which induces Brønsted acidity, or by an extra-framework cation, leading to Lewis acidity. Thanks to these properties, zeolites can replace inorganic acids in acid catalysed reactions, with the very important advantages of recyclability and the possibility of tuning the acid strength and type. Working with zeolites eliminates volatile and toxic solvents, and halogenated compounds such as alkylating agents. On this basis they are frequently used for the synthesis of fine chemicals [17], as will be presented in a later chapter, and, somehow related, for the 
production of chemicals from biomass [18-20]. This section presents examples of these advantages. They mainly refer to H-zeolites and Sn-Beta zeotype [21]. The processes analysed are depicted in Figure 2.

\subsection{Transformation of the primary products of the cellulose fragmentation: sucrose, glucose, fructose, xylose, arabinose, galactose, mannose}

The isomerization of glucose into fructose is a large-scale reaction typically performed by enzymes, which have as their main disadvantage deactivation and large reaction volumes [22]. Besides the production of syrups, this reaction is also a potential route for the production of chemicals from biomass. In this regard, recyclable catalysts are necessary.

Ca- and Ba-exchanged $\mathrm{A}, \mathrm{X}$ and $\mathrm{Y}$ zeolites were found less selective in this reaction, whereas those with milder basicity such as Na-X and K-X zeolites were found to achieve the isomerization of glucose into fructose with a selectivity of about 9o \%. [23]. However, this high selectivity to fructose is only obtained at low glucose conversions, below $25 \%$. Furthermore, it was found that a significant amount of the cation leached into water (around $15 \%$ in the case of monovalent ion exchanged $\mathrm{X}$ zeolites).

Large-pore zeolite containing tin (Sn-Beta) emerged as particularly effective to catalyse carbohydrate transformations. It is able to isomerize hexoses, pentoses and trioses by intramolecular hydride and carbon shift reactions in various solvents, including aqueous media, with high activity and selectivity. [24-27]. The properties of the large-pore zeolite have a dominant effect on these reactions. The reaction is very slow over Sn-MCM-41 or even does not proceed over a medium-pore zeolite like Sn-MFI [28].

\subsection{Hydrolytic hydrogenation of glucose to sugar alcohols or hexitols}

The hydrolytic hydrogenation of cellulose/glucose to sugar alcohols offers an alternative to petrochemicals and to the current environmental problems [29]. Such catalytic processes would provide promising platform molecules for oxygenates and liquid alkanes [30]. Sorbitol is an eloquent example. It can be used as a sweetener, dispensing agent and humectant in pharmaceuticals, cosmetics and textiles, as well as for the further chemical synthesis of surfactants [31]. To obtain it, the hydrolytic hydrogenation 
of cellulose in the presence of metallic ( $\mathrm{Ir}, \mathrm{Ru}, \mathrm{Rh}, \mathrm{Pd}) / \mathrm{BEA}$ bifunctional catalysts may produce sorbitol with yields of $55 \cdot 3-72.8 \%$ [32]. The selectivity to sorbitol correlated with the d-band width of the metal, i.e.: Ir > $\mathrm{Ru}>\mathrm{Rh}>\mathrm{Pd}$. However, besides the metal nature, both the acid groups of BEA zeolite and in the conversion of monosaccharides, the concentration of adsorbed hydrogen species on the zeolite surface played key roles in the formation of sorbitol. In fact, it was later shown that the rate of hexitol formation increases with the degree of zeolite dealumination [33]. The potential of bifunctional $\mathrm{Ru} / \mathrm{H}$-USY catalysts for the total conversion of cellulose to sugar alcohols or hexitols in hot liquid water (HLW) is limited by its physicochemical stability, i.e. the long-term catalytic performance of acid sites and noble metal functionality. Zeolite desilication is the main zeolite degradation mechanism in HLW, in which USY zeolite stability depends on two main parameters - framework and extra-framework aluminium content. The former protects the zeolite lattice by counteracting hydrolysis of framework bonds, and the latter, when located at the external crystal surface, prevents solubilization of the zeolite framework as a result of its low water-solubility.

\subsection{Production of HMF, furfural and 2,5-furandicarboxylic acid}

5-Hydroxymethylfurfural (HMF), furfural and 2,5-furandicarboxylic acid (FDCA) are derivatives of furan compounds, which were listed among the top 10 value-added bio-based chemicals by the US Department of Energy [34]. To obtain it from cellulose, from a mechanistic point of view, glucose needs to be isomerized to fructose, followed by dehydration to HMF. Accordingly, the process requires an isomerization catalyst for the transformation of glucose to fructose and a second component able to catalyse the dehydration [35].

Dehydration of fructose into HMF was found to depend on both acidic and structural properties of the zeolites used [36]. H/Y faujasites and $\mathrm{H}$-Mordenites with $\mathrm{Si} / \mathrm{Al}$ ratios of 15 and 11 were used. Shape-selective properties and, particularly, the absence of cavities are very important, allowing selectivities over 9o-95\% for H-Mordenites [37].

Dehydration of D-xylose into furfural was also reported in liquidphase over various H-zeolites (H-furrieries, H-Beta, H-ZSM-5, H-Y and $\mathrm{H}-\mathrm{Mordenite)}$ with various $\mathrm{Si} / \mathrm{Al}$ molar ratios in different solvent systems: water, dimethyl sulfoxide (DMSO), and a mixture of water and toluene [38]. Conversion and furfural yield generally decreased with an increasing $\mathrm{Si} / \mathrm{Al}$ 
molar ratio, which was closely related to the accessibility of the acid sites, and depended on the solvent: water/toluene $>$ DMSO > water. Thus, H-Beta (25) showed the highest furfural selectivity in water and water/toluene, while H-Mordenite (20) showed the highest furfural selectivity in DMSO. Phase modifiers like DMSO and poly(1-vinyl-2-pyrrolidinone) also helped to suppress undesired side reactions [39]. However, the catalyst should also show high stability in highly acidic aqueous environments to allow coupling the isomerization with other acid-catalysed reactions, namely, the dehydration of the isomerized product. Sn-Beta zeotype has also been reported to catalyse the isomerization of xylose [40].

DFT calculations explained the role of Sn in these reactions [41], indicating that its main contribution is to promote the transformation of the acyclic glucose to a deprotonated fructose intermediate. The catalytic cycle is completed by the closure of the fructofuranose ring and the protonation of the anionic carbohydrate intermediate bound to the Sn site. These steps are facilitated by water molecules, which mediate the proton transfer reactions between the different oxygen-containing moieties of the carbohydrate. According to these calculations, the Sn(IV) tetrahedral lattice site and the hydroxylated $\mathrm{SnOH}$ species exhibit very similar reactivity.

The conversion of cellulose to HMF using a complex acid catalyst composed of $\mathrm{CrCl}_{2} /$ Zeolite/BMIMCl (ionic liquid 1-butyl-3-methylimidazolium chloride) was reported to be active at low catalyst loading and low temperature $\left(<120^{\circ} \mathrm{C}\right)[42]$. The role of zeolite in this process was to promote cellulose hydrolysis and to slow down the decomposition of the HMF product. Its effect varied in the order: $\mathrm{H}-\mathrm{Y}>\mathrm{H}-\mathrm{Beta}>\mathrm{H}-\mathrm{MOR}>\mathrm{H}-\mathrm{ZSM}-5$.

Mesoporous $\mathrm{Nb}_{\mathrm{x}} \mathrm{W}_{8-\mathrm{x}}$ oxides synthesized by an evaporation-induced self-assembly method created large amounts of Lewis and Brønsted acid sites, which promoted the isomerization of glucose to fructose as well as its following dehydration to HMF. Mannose was also formed through the epimerization of glucose [43].

5-benzyl-2-furoic acid derivatives are important intermediates for the preparation of a variety of compounds with biological activity [44]. In the classic protocols they are produced by a Friedel-Crafts alkylation with chlorinated acid derivatives using $\mathrm{AlCl}_{3}$ or $\mathrm{ZnCl}_{2}$ as Lewis acid catalysts. To obtain methyl 5-hydroxymethyl-2-furoate from HMF, a heterogeneous catalytic alternative comprises consecutive reactions using a two-component catalyst $\left(\mathrm{Au} / \mathrm{TiO}_{2}\right.$ and an acid catalyst). $\mathrm{Au} / \mathrm{TiO}_{2}$ catalyses the oxidative esterification of HMF, followed by its conversion into methyl 5-benzyl-2-furoate by alkylation of the benzene derivative of interest 


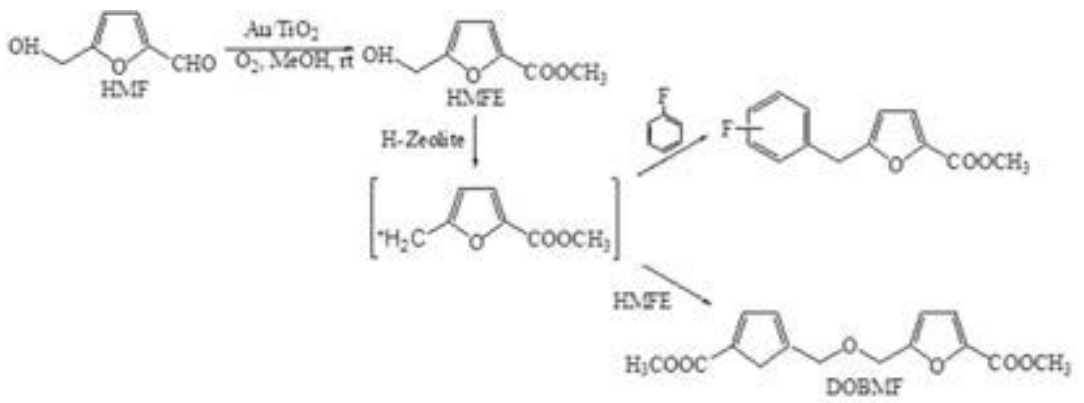

Figure 3. The production of 5-benzyl-2-furoate in the presence of a two-dimensional zeolite. (HMF = 5-hydroxymethylfurfural, HMFE = 5-hydroxymethyl furoic acid methyl ester, DOBMF = dimethyl 5,5'-(oxybis(methylene))bisfuran-2-carboxylate). Reprinted with permission from ref. [45]. Copyright 2016 American Chemical Society.

over the solid acid catalyst (Figure 3). For this last step, a number of zeolites with similar $\mathrm{Si} / \mathrm{Al}$ ratios including H-Beta ( $\mathrm{Si} / \mathrm{Al}=12$ and 14$), \mathrm{MCM}-22$ ( $\mathrm{Si} / \mathrm{Al}=15)$, USY $(\mathrm{Si} / \mathrm{Al}=12), 2 \mathrm{D}$ zeolite ITQ-2 $(\mathrm{Si} / \mathrm{Al}=15)$, and a hierarchical mesoporous zeolite USY-HYM zeolite $(\mathrm{Si} / \mathrm{Al}=5 \cdot 3)$ were considered [44]. The catalytic results demonstrated the need for a balance between acidity and diffusional constraints. Large pore tridimensional zeolites, such as Beta and USY, showed an adequate acidity to carry out the reaction but they presented strong product diffusion limitations that led to rapid deactivation. On the other hand, MCM-41 had pores large enough to allow an easy product diffusion but exhibited a too low acidity for this reaction. Finally, delaminated ITQ-2 zeolite combined both requirements and thus allowed high reaction rates and selectivity.

\subsection{Cellulose to levulinic acid}

Levulinic acid (LA) represents a versatile bio-based chemical product of the valorization of cellulose and is an important feedstock for the production of many chemical commodities (Figure 4) [45]. It can be obtained by HMF transformation and the presence of a carbonyl and a carboxylic acid group confers to this molecule the properties of a building block for various chemicals [46]. On this basis, the catalytic conversion of carbohydrates to LA over solid catalysts has received much attention over the last few decades. Since these reactions require the presence of strong Brønsted acids, H-zeolites have been largely investigated. Zeolite 


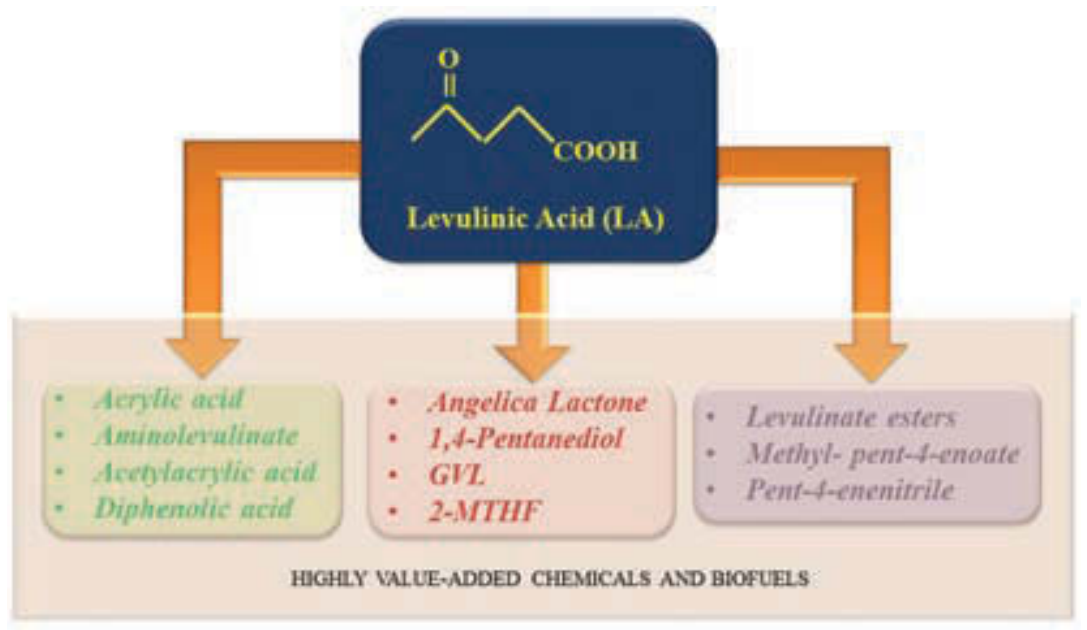

Figure 4. Chemical commodities produced from levulinic acid [45].

catalysts like $\mathrm{H}_{-\mathrm{ZSM}-5}$ have economic advantages over resin catalysts, in particular, they can be easily regenerated by a calcination treatment after they are deactivated [47]. However, employing these catalysts may result in significantly lower LA yields, especially when high LA concentrations are desired in the product stream. This disadvantage can be eliminated by utilising biphasic systems: an aqueous layer that contains the zeolite and an organic layer to extract the LA produced [47]. 2-sec-butylphenol, 4- $n$-hexylphenol and 4-propylguaiacol already demonstrated to be effective extracting agents for the production of furfural and LA in these biphasic systems [47]. Another advantage of the solvents is that they can be synthesized directly from biomass (i.e. lignin). Hybrid catalysts consisting of a homogeneous $\left(\mathrm{CrCl}_{3}\right)$ and a heterogeneous (zeolite $\mathrm{Y}$ ) catalyst have been indicated as effective in this reaction as well $[48,49]$.

The efficient production of levulinate esters is another important reaction in the valorization of biomass. Zeolites were largely investigated for this esterification because of their adjustable acidity, easy recyclability, and potential economic and environmental benefits. However, levulinic acid esterification with ethanol to ethyl levulinate over H-USY, H-BEA, H-ZSM-5, $\mathrm{H}-\mathrm{MOR}$ indicated that they are not active enough to be considered in an industrial application [50]. Esterification on these materials occurred with smaller yields compared to other functionalized porous structures, like sulfonic-acid-functionalized SBA- 15 catalyst [51]. 


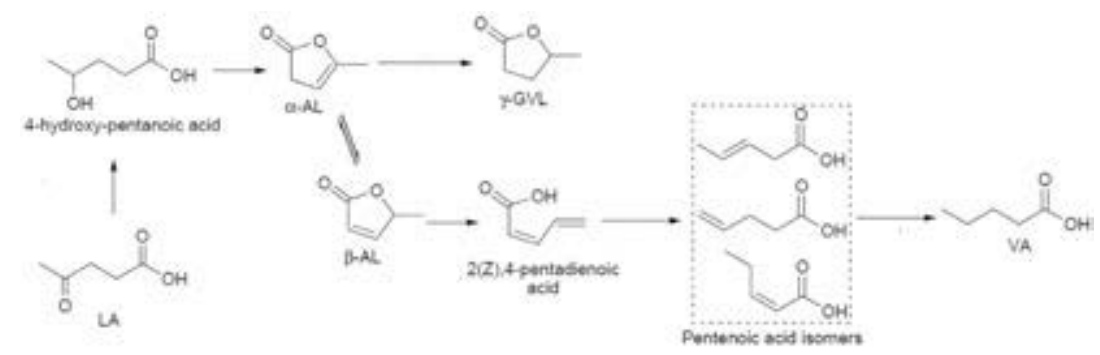

Figure 5. Reaction pathway for the microwave-assisted hydrogenation of LA in presence of FA using $\mathrm{Pd} / \mathrm{C}$ catalyst. Adapted from [53]. CC BY 4.0.

\subsection{Levulinic acid hydrogenation to $\gamma$-valerolactone}

Levulinic acid can be transformed to a series of other valuable chemicals. Among these, $\gamma$-valerolactone (GVL) is one of the most important. Several catalytic approaches to produce it have been reported. Qi and Horváth [52] demonstrated that working with a homogeneous catalyst with GVL as solvent it is possible to produce GVL directly from fructose having HMF and levulinic acid as the only intermediates.

As an alternative to noble metal catalysts, supported iron oxide nanoparticles on Al- and Zr-SBA-15 were investigated for the hydrogenation of levulinic acid to $\gamma$-valerolactone [53]. Reactions were carried out under continuous flow, with formic acid as the hydrogen donating agent to effectively replace high pressure H2. Since $\alpha$-angelica lactone can suffer an isomerization to $\beta$-angelica lactone leading to pentenoic acid isomers and valeric acid (Figure 5), the control of the selectivity is very important in this reaction.

\subsection{Oxidation of glucose to gluconic acid, glucuronic acid, tartaric acid, glycolic acid, and glyceric acid}

The use of redox zeolites and redox pillared clays for the valorization of biomass was suggested long ago [54]. The oxidation of D-glucose to gluconic acid, glucuronic acid, tartaric acid, glycolic acid and glyceric acid may also occur with hydrogen peroxide as oxidant over several zeolites and Ti-containing zeolites, like TS-1 or Ti-MCM-41 [55]. Using zeolites (ZSM-5, L, Y, Mordenite) gluconic acid is the main reaction product, having glucoronic and tartaric acids as main by-products. The presence of titanium preserves the high selectivity to gluconic acid but the oxidation by-products change to glycolic acid. 


\subsection{Production of lactic acid and methyl lactate}

Lactic acid is an important platform molecule in the synthesis of a wide range of chemicals $[56,57]$. Lactic acid fermentation is typically performed by lactic acid bacteria, which convert simple carbohydrates like glucose, sucrose, or galactose to lactic acid.

Lewis acidic Sn-Beta zeotype also allowed the direct formation of methyl lactate from common sugars [58]. The conversion of sucrose in methanol at $160^{\circ} \mathrm{C}$ afforded methyl lactate with a yield of $68 \%$. The conversion of pentoses and hexoses into methyl lactate over Sn-Beta showed a dependence on the nature of the saccharide. Pentoses are converted to methyl lactate in slightly lower yields $(\sim 40 \%)$ than those obtained from hexoses $(\sim 50 \%)$, but higher yields of glycolaldehyde dimethyl acetal are observed from pentoses. This finding agrees with a reaction pathway involving the retro aldol condensation of the sugars to yield triose and glycolaldehyde from pentoses, and two trioses from hexoses. When reacting glycolaldehyde (formally a $\mathrm{C}_{2}$-sugar) in the presence of Sn-Beta, aldol condensation occurs, leading to the formation of methyl lactate, methyl vinylglycolate and methyl 2-hydroxy-4-methoxybutanoate. By contrast, when converting the sugars in water at low temperature $\left(100^{\circ} \mathrm{C}\right)$, Sn-Beta catalyses the isomerization of sugars (ketose-aldose epimers) rather than the formation of lactates [59].

High selectivity to the desired lactate product was achieved with an ordered mesoporous material (OMM) Sn-MCM-41 [6o]. However, a more elaborated Lewis acid zeotype catalyst consisting of two components (MCM-41 filled with a porous polyaromatic hydrocarbon network) improved the performance in this reaction (Figure 6) [61]. Modification of the organic part with functional groups exhibiting mild Brønsted acidity and of the inorganic part by grafting Lewis acid $\mathrm{Sn}(\mathrm{IV})$ enabled a catalyst able to transform trioses and aldo- and ketohexoses (fructose) into lactic acid in aqueous medium $(\mathrm{R}=\mathrm{H})$ or into alkyl lactates $(\mathrm{A})$ in alcoholic solvents ( $\mathrm{R}=$ alkyl). Yields to lactate correlate with the length of the alcohol radical, octanol providing the highest values.

In aqueous solutions without alkali, the efficient preparation of lactic acid through the direct catalysis of sugars is hindered by the dehydration side reaction to 5 -hydroxymethylfurfural. This is due to Brønsted acidity, which originates from organic acids [62]. It was suggested that this could be avoided by using Zn-Sn-Beta prepared via solid-state ion exchange. In water under ambient air pressure, without a base, a sucrose conversion exceeding $99 \%$ with a lactic acid yield of $54 \%$ was achieved within 2 hours at $190{ }^{\circ} \mathrm{C}$. Studies of the acid and base properties of the $\mathrm{Zn}$-Sn-Beta zeolite 


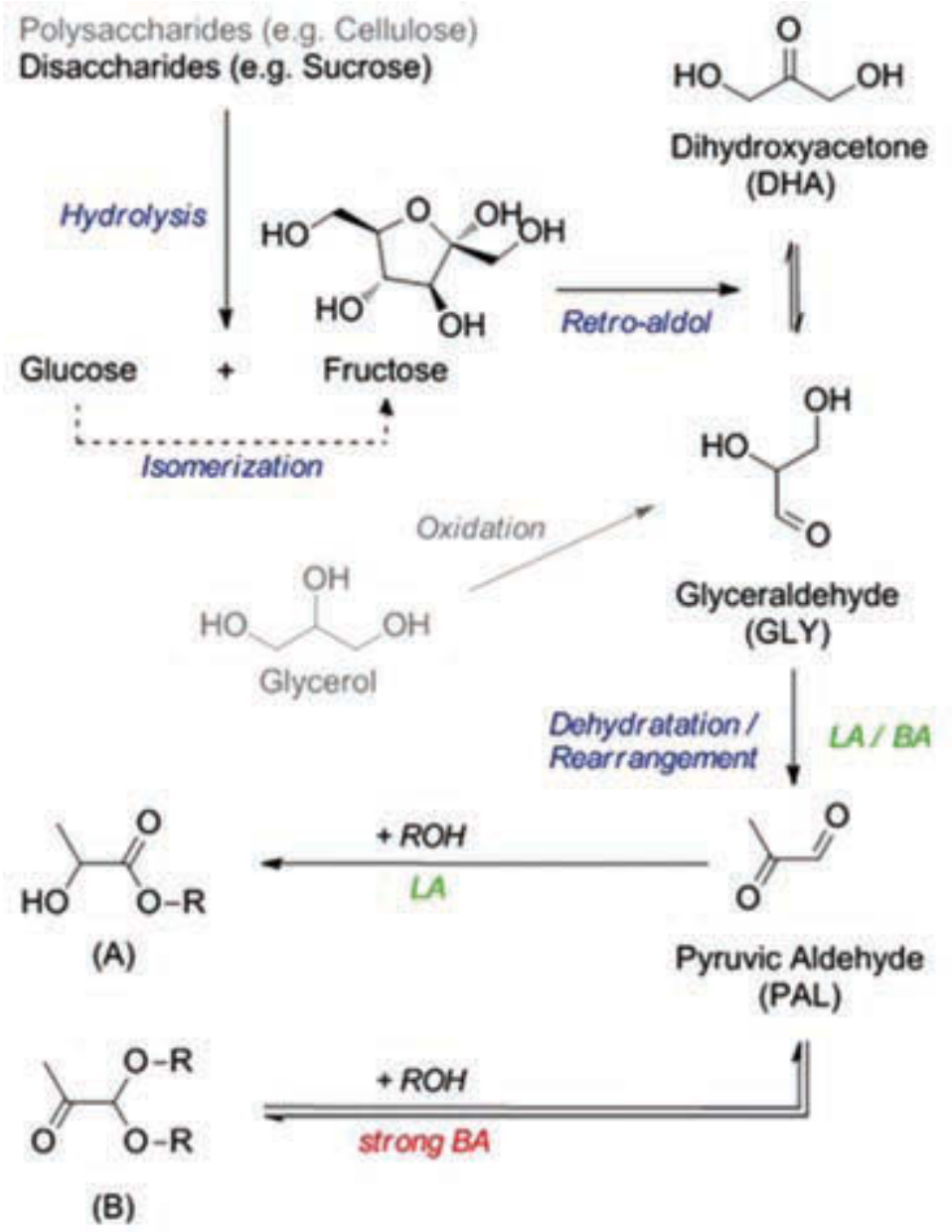

Figure 6. Conversion of monosaccharides like trioses and aldo- and ketohexoses (fructose) into lactic acid in aqueous medium $(R=H)$ or into alkyl lactates $(A)$ in alcoholic solvents $(R=$ alkyl). The side reaction leading to the formation of pyruvic aldehyde dialkyl acetal $(B)$ is undesired $-\mathrm{LA}=$ Lewis acid; $\mathrm{BA}=$ Brønsted acid. Reprinted with permission from ref. [61]. Copyright 2012 American Chemical Society.

suggest that the introduction of Zn into the Sn-Beta zeolite enhanced both the Lewis acid and base sites. The base sites inhibited a series of side reactions related to fructose dehydration to 5 -hydroxymethylfurfural and its subsequent decomposition.

Indeed, Sn-Beta zeolite was also found to be a highly active catalyst for the conversion of triose sugars (1,3-dihydixyacetone in Figure 6$)$ to lactic acid. In water, once they are produced, isomerization takes place to form 
lactic acid in very high yields at $125^{\circ} \mathrm{C}$ [63]. Methanol reaction at $80^{\circ} \mathrm{C}$, is also followed by esterification, leading to methyl lactate in quantitative yields. $\mathrm{H}-\mathrm{USY}(\mathrm{Si} / \mathrm{Al}=6)$ is also reasonably active in this reaction [64].

\subsection{Aldol condensation of fural aldehydes}

Zeolites have also been considered for aldol condensation of fural aldehydes. Nitrided zeolite Y was used in the aldol condensations of furaldehydes with acetone and propanal, showing comparable activity to $\mathrm{MgO}-\mathrm{ZrO}_{2}$ and much higher than that over $\mathrm{NaY}[65]$. However, under reaction conditions part of the nitrogen leached, resulting in the loss of catalytic activity [65]. H-zeolites of different structural types also showed appreciable activity in the aldol condensation of furfural with acetone and resulted in the formation of products, which are usually obtained using basic catalysts $[66,67]$. However, the reaction on these zeolites can continue with the dimerization of the classical condensation products. Large-pore three-dimensional BEA and FAU zeolites afforded higher furfural conversion than medium-pore MFI or large-pore mono-dimensional MOR [66]. Another disadvantage of these catalysts is the quick formation of coke inside the zeolite pores, requiring regeneration of the catalysts.

\section{Lignin valorization}

Catalytic valorization of lignin for the production of renewable chemicals has been recently reviewed [11]. The participation of zeolites in this effort is merely associated with biomass fast-pyrolysis. Such technology upgrades solid biomass as it yields products with higher energy density, and is also more economical than the alternative technologies of gasification $[68,69]$. The composition of the produced bio-oil depends on the origin of the lignin. Softwood lignins yielded exclusively guaiacyl derivatives, coniferaldehyde and coniferyl alcohol, hardwood lignins gave rise to guaiacyl and syringyl derivatives, among which syringaldehyde, coniferyl alcohol and sinapyl alcohol were the most abundant. Grass lignins, represented by bamboo lignin, yielded $p$-vinylphenol as the main compound. In addition, other guaiacyl and syringyl pyrolysis products were identified, too [70].

In situ electron paramagnetic resonance (EPR) measurements and model compounds studies reveal two main decomposition routes in this process - firstly, the homolytic fission of the weakest bond-forming radicals 


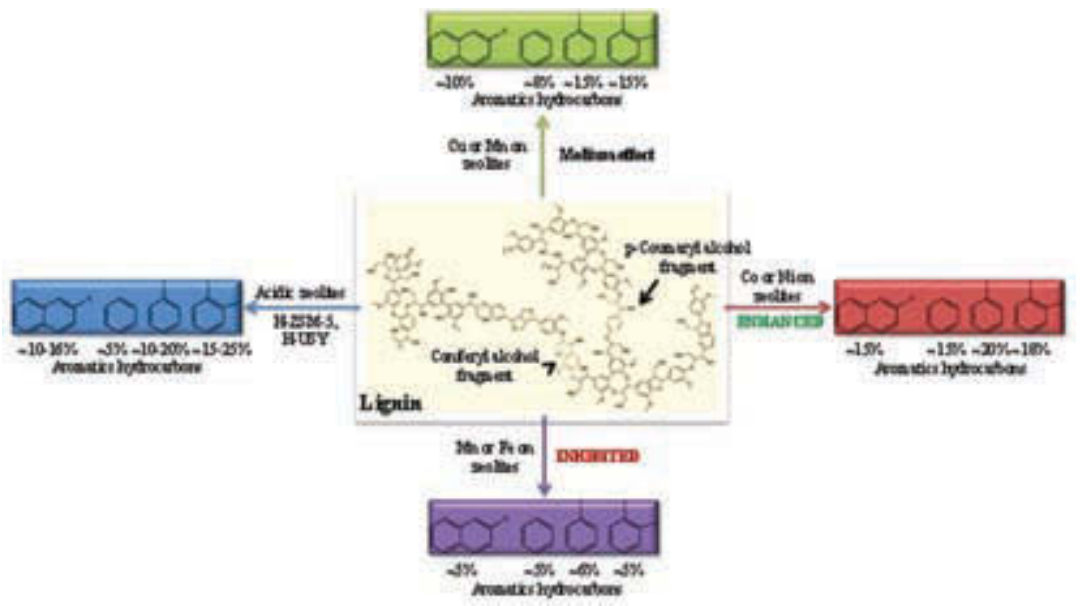

Figure 7. Zeolite transformation of the pyrolysis oil. Copyright $\odot$ Swiss Chemical Society: CHIMIA, ref. [71]. DOI: https://doi.org/10.2533/chimia.2015.597

and, secondly, the radical initiation leading to different radicals, which further rearrange or recombine depending on the nature of the radicals [71]. However, there is a significant potential to control the selectivity by varying catalysts and reaction conditions [72-74]. The formation of aromatic hydrocarbons is enhanced over zeolite-supported Co and $\mathrm{Ni}$ catalysts, (Figure 7). The intermediates are stabilized by adsorption on the pores in materials without acidity, such as silicalite, thus increasing the yield of liquid without changing the liquid products distribution. In the presence of strongly acidic zeolites, such as H-USY and $\mathrm{H}_{-} \mathrm{ZSM}_{5}$ of low Si/Al ratio, complex reactions, such as dehydration, decarboxylation, dealkylation, cracking, isomerization and oligomerization are involved.

To preserve the catalyst activity, the establishment of a step of pyrolytic lignin deposition at $400{ }^{\circ} \mathrm{C}$ avoids the blockage of the on-line catalytic bed and attenuates the deactivation of a HZSM- 5 zeolite based catalyst used for hydrocarbon production [75]. As mentioned above, the stability of the zeolites is a critical issue in these processes. One of the major concerns is their hydrothermal stability in the presence of steam or hot water. Therefore, given the high water content in pyrolysis oils and biomass as a whole, as well as in aqueous processes, the selection of H-USY and $\mathrm{H}-Z S M_{5}$ is reasonable. These materials, exhibit a good stability in liquid water between 150 and $200^{\circ} \mathrm{C}$ regardless of their $\mathrm{Si} / \mathrm{Al}$ ratio $[76]$.

Biomass pyrolysis oil contains oxygenate compounds that may be partially transformed to hydrocarbons on acid catalysts to obtain raw a material for the petrochemical industry (light olefins and benzene, toluene, 
and xylene). The utilization of a catalyst based on HZSM-5 zeolite led to a product distribution similar to that obtained from the transformation of light alcohols $[77,78]$.

\section{Metal-organic frameworks for the upgrading of biomass}

So far, we have demonstrated the use of zeolites in different reactions involved in the production of platform molecules derived from biomass. This is due to the structural properties of these porous materials that present a $3^{\mathrm{D}}$ framework with high surface areas and suitable porous structures, as well as chemical and thermal stabilities. The $3 \mathrm{D}$ structure leaves confined spaces with limited dimensions where only certain substrates, transition states or products are allowed, resulting in a control of the process called shape selectivity [79]. Moreover, zeolites, which have coordinatively unsaturated metal sites, present strong Lewis acidity and can also have Brønsted acidity, both of them useful for biomass reactions such as hydrolysis. Nevertheless, despite the advantages of zeolites and the wide number of possible structures [8o], higher chemical adaptability of the zeolite-based catalysts is required to improve yields and selectivities in biomass upgrading and to allow one-pot syntheses. Additionally, textural properties of zeolites also require a more specific design to control the transport phenomena during the catalytic reactions and to enhance the density of active sites. Therefore, a step forward is required in the design of catalysts for reactions such as hydrolysis, pyrolysis, condensation, isomerization, deoxygenation, hydrogenation, and oxidation, working under complex chemical environments with multiple functional groups and in the presence of water.

In this sense, a new type of porous materials, with a huge potential for catalysis, has been developed over the last 25 years. These are metal-organic frameworks (MOFs), also named porous coordination polymers (PCPs), which are composed of meal ions and various organic ligands [81-87]. MOFs can be classified into different families according to the inorganic framework, as was highlighted by Farrusseng et al. [87]. There are different systems, such as a) open-framework coordination polymers made from oD inorganic, hybrid or isolated metal clusters connected by bridging organic polytopic ligands, or organic-inorganic hybrid materials in which the inorganic moieties can be organized into b) $1 \mathrm{D}$ chains or c) $2 \mathrm{D}$ layers separated by organic pillars. These materials have demonstrated their high potential to outperform even zeolites in some reactions due to their tunability provided by the different compositions of organic ligands and metallic clusters [87]. 
Table 1. MOFs vs zeolites: a comparison of the main properties of both types of materials. Adapted from references $[79,80]$.

\begin{tabular}{|c|c|c|}
\hline Properties & MOFs & Zeolites \\
\hline $\begin{array}{l}\text { Thermal } \\
\text { stability }\end{array}$ & Stable below $300^{\circ} \mathrm{C}$ & Stable above $450^{\circ} \mathrm{C}$ \\
\hline $\begin{array}{l}\text { Chemical } \\
\text { stability }\end{array}$ & $\begin{array}{l}\text { Limited chemical stability } \\
\text { specially to } \mathrm{H}_{2} \mathrm{O} \text { in most cases }\end{array}$ & $\begin{array}{l}\text { Stable to solvents, acids, oxidizing } \\
\text { and reducing agents }\end{array}$ \\
\hline $\begin{array}{l}\text { BET surface } \\
\text { area }\end{array}$ & Around $1,000-10,000 \mathrm{~m}^{2} \mathrm{~g}^{-1}$ & Around $200-500 \mathrm{~m}^{2} \mathrm{~g}^{-1}$ \\
\hline Pore volume & Over $1 \mathrm{~cm}^{3}$ & $0.1-0.5 \mathrm{~cm}^{3}$ \\
\hline $\begin{array}{l}\text { Metal site } \\
\text { density }\end{array}$ & High & Low \\
\hline Lewis acidity & Accessible framework metal ions & Accessible framework metal ions \\
\hline $\begin{array}{l}\text { Brønsted } \\
\text { acidity }\end{array}$ & Introducible through organic linker & $\begin{array}{l}\text { Bridging } \mathrm{Si}(\mathrm{OH}) / \mathrm{Al} \text { hydroxyl } \\
\text { groups }\end{array}$ \\
\hline Basicity & Introducible through organic linker & From framework oxygen atoms \\
\hline $\begin{array}{l}\text { Active site } \\
\text { environment }\end{array}$ & $\begin{array}{l}\text { More hydrophobic, but linker- } \\
\text { dependent }\end{array}$ & $\begin{array}{l}\text { Mostly hydrophilic but can be } \\
\text { made hydrophobic }\end{array}$ \\
\hline $\begin{array}{l}\text { Additional } \\
\text { features }\end{array}$ & $\begin{array}{l}\text { Chiral functionalities, flexible and } \\
\text { stimuli responsive behaviour }\end{array}$ & - \\
\hline Reactivation & $\begin{array}{l}\text { Washing procedures; thermal } \\
\text { treatment not possible }\end{array}$ & By thermal treatment \\
\hline
\end{tabular}

The application of MOF catalysts is recent [8o], and the use of MOFs-based catalysts for the upgrading of lignocellulosic biomass is even more recent. In 2011, Akiyama et al. [88] presented one of the first works on the synthesis of a new PCP decorated with sulfonic acid functional groups for the hydrolysis of cellulose. Recently, Herbst and Janiak have presented a comprehensive review about the use of MOF catalysts in the transformation of biomass into valuable fine chemicals [80]. This includes the state of the art as well as the challenges and perspectives in this field of MOF applications. Furthermore, this review not only summarizes the few works devoted to this end but also deeply analyses the advantages and drawbacks of these types of materials and compares them to zeolites. Given the scope of this book, we have adapted some of the main relevant contrasts made by these authors in Table 1. 
The application of MOFs in the transformation of biomass is not easy since, although over 20,000 types have been reported in literature, only water-stable MOFs would be applicable in the sort of reactions cited above. Furthermore, certain thermal and chemical stabilities are required, thus reducing the number of suitable MOF-based catalysts considerably $[80,89,90]$. Thus, the stability of MOFs is an important issue that has to be controlled and carefully addressed, especially when reactions are carried out in the presence of water, which is a typical situation for the reactions involving biomass-derived feedstocks $[80,90]$. Concerning the relevance of the stability of MOFs for catalytic applications, Burtch et al. [91] have presented a comprehensive review defining some concepts on the water stability of MOFs, which can be considered during the design of MOF catalysts for the transformation of biomass. In this review, a broad classification of the huge number of MOFs that have been experimentally characterized after water exposure is presented, taking into account thermodynamic and kinetic stabilities. Thermodynamic stability considers chemical aspects, such as the metal-ligand bond strength or the lability in water and the possible variables that may affect them during the reactions. On the other hand, kinetic stability deals with aspects such as access to the active sites. From both, the hydrophobicity and the steric factors will determine if the MOF-based catalysts are suitable for reactions including water [91].

Another remarkable advantage of MOF catalysts is their high adsorption capacity and the possibility of achieving controlled pore sizes. In fact, to process the big molecules derived from the biomass deconstruction, materials with big pores are required to enhance the selectivity in the adsorption of reactants and in the desorption of products to allow one-pot procedures. In their review, Farrusseng et al. [87] presented the influence of the porous architecture on selectivity in different reactions. In this sense, the superior adsorption abilities of MOF catalysts over zeolites is demonstrated from results like those by Kruger et al. [92]. In this work, the pore sizes of different zeolite catalysts and the diameter of platform molecules were compared by means of simulations. While the zeolite structure with the largest pore sizes is $\mathrm{H}-\mathrm{Y}$ with $7 \cdot 5 \AA$, some of the most suitable MOFs systems for the upgrading of biomass present larger pore diameters. For instance, MIL-101Cr has pores of 29 and $34 \AA$ and pore windows of 12 to ${ }_{15} \AA$ [92], which made this system suitable for glucose recovery [93]. The unusual adsorption abilities of some MOFs has also been confirmed by Yabushita et al. [94], who observed that NU-10oo MOF adsorbs cellobiose and lactose dimers from aqueous solution in amounts exceeding $1250 \mathrm{mg} \mathrm{g}^{-1}$ while completely excluding adsorption of the glucose monomer. The high 
selectivity of the adsorption process in these materials, which results in a selective molecular recognition, seems to be due to the number of favourable $\mathrm{CH}-\pi$ interactions between the sugar with pyrene units and the studied MOF.

\subsection{Transformation of cellulose and hemicellulose carbohydrate polymers using MOF catalysts}

As remarked above, the work by Akiyama and coworkers [88] addressed the high potential of MOF catalysts for transforming biomass-derived products into biofuels or high added value chemicals. This will contribute to the development of biorefineries, aiming to transform residual biomass feedstocks rather than those derived from food crops so avoiding competition with the food supply. In this work, the authors modified the structure of a typical MIL-101 MOF introducing sulfonic acid groups on its pore surface for use in cellulose hydrolysis [88]. After comparing the catalytic performance of this system with that of different acid catalysts, such as Amberlyst-15, this MOF catalyst demonstrated clean catalytic activity and high Brønsted acidity but low yields to mono- and disaccharides due to the low solubility of crystalline cellulose in water. However, the MOF catalyst exhibited a considerable robustness in boiling water and strongly acidic conditions. Further studies from this research team about the use of functionalized MIL-101 catalysts have confirmed that the high stability and availability of its acid centres and the open metal sites resulted in the enhancement of glucose-to-fructose conversion [95]. In addition, the structural features in coordination of the chromium sites in this type of materials led to performances comparable to those of homogeneous catalysts, demonstrating the high specificity that can be achieved with these materials $[80,95]$.

Chen et al. presented a different approach to the conversion of cellulose, starting from a MIL-101 MOF but with different modifications [96]. In this case, water-tolerant phosphotungstic acid (PTA)/MOF-supported Ru catalysts are bifunctional (metal/acid) catalysts for obtaining cellulose- and cellobiose-derived alcohols. The metal/acid balance was studied in order to establish optimal conditions for the production of alcohols: selectivities to sorbitol of $57.9 \%$ and $95.1 \%$ were achieved in the conversion of cellulose and cellobiose, respectively [96].

Recently, Huang et al. [97] reported the use of a new 3D MOF/graphene catalyst prepared by in situ growth of zeolitic imidazolate framework (ZIF-8) 
nanoparticles inside the pores of a hydrogel. In this case, cellulose was dissolved in alkaline aqueous solution and consequently degraded over the catalyst under hydrothermal conditions, reaching total conversion with formic acid as the main product, along with oxalic and acetic acids.

Although the use of MOF catalysts for the transformation of biomass is an emerging topic, most works have focused on the transformation of molecules derived from cellulose and hemicellulose rather than lignin. This is due to the complex transformation of the lignin molecule, as a result of its complex structure and multiple possibilities of selective rupture in smaller molecules. Table 2 presents a comprehensive summary of works devoted to the transformation of cellulose/hemicellulose-derived molecules using MOF catalysts. It includes all the references cited by Herbst and Janiak [8o] and the newer works presented up until now. As can be inferred from the table, two families of MOFs have principally been studied as catalysts for these reactions: MIL-101(Cr) and UiO-66 - due to the thermal and water stability in both cases, as well as the contribution of strong and stable acid sites.

Lignin is also a potential source of renewable organics with high a content of oxygenated functional groups. However, the strong chemical bonds comprising this polymer make its transformation particularly difficult. Furthermore, the complexity of the obtained mixtures of products is also important because in such a multi-functional chemical environment oxygenated molecules may tend to re-polymerize. Despite this, the development of efficient heterogeneous catalysts for the selective cleavage of $\mathrm{C}-\mathrm{O}$ aromatic bonds in lignin has been recently demonstrated [98]. This verifies the first report by Stavila et al. [99] concerning the use of MOF-based catalysts for the hydrogenolysis of carbon-oxygen ether bonds, which are common linkages in oxygenated molecules derived from lignin.

\subsection{Transformation of lignin over MOF catalysts}

To date, only vanillin has been analysed as a model to explore the hydrogenation and deoxygenation routes of lignin. Recently, Zhang et al. [114] have studied the properties of $\mathrm{SO}_{3} \mathrm{H}-\mathrm{MIL}-1 \mathrm{Ol}(\mathrm{Cr})$, encapsulated $\mathrm{Pd}$ nanoparticles in the mesoporous cages of the catalysts and obtained an efficient catalyst for the hydrodeoxigenation of vanillin. In this case, the developed $\mathrm{Pd} / \mathrm{SO}_{3} \mathrm{H}-\mathrm{MIL}-1 \mathrm{O}(\mathrm{Cr})$ catalysts presented high catalytic activity in tandem hydrogenation-deoxygenation reactions, and could be recycled several times without any apparent loss in activity or selectivity. The high 


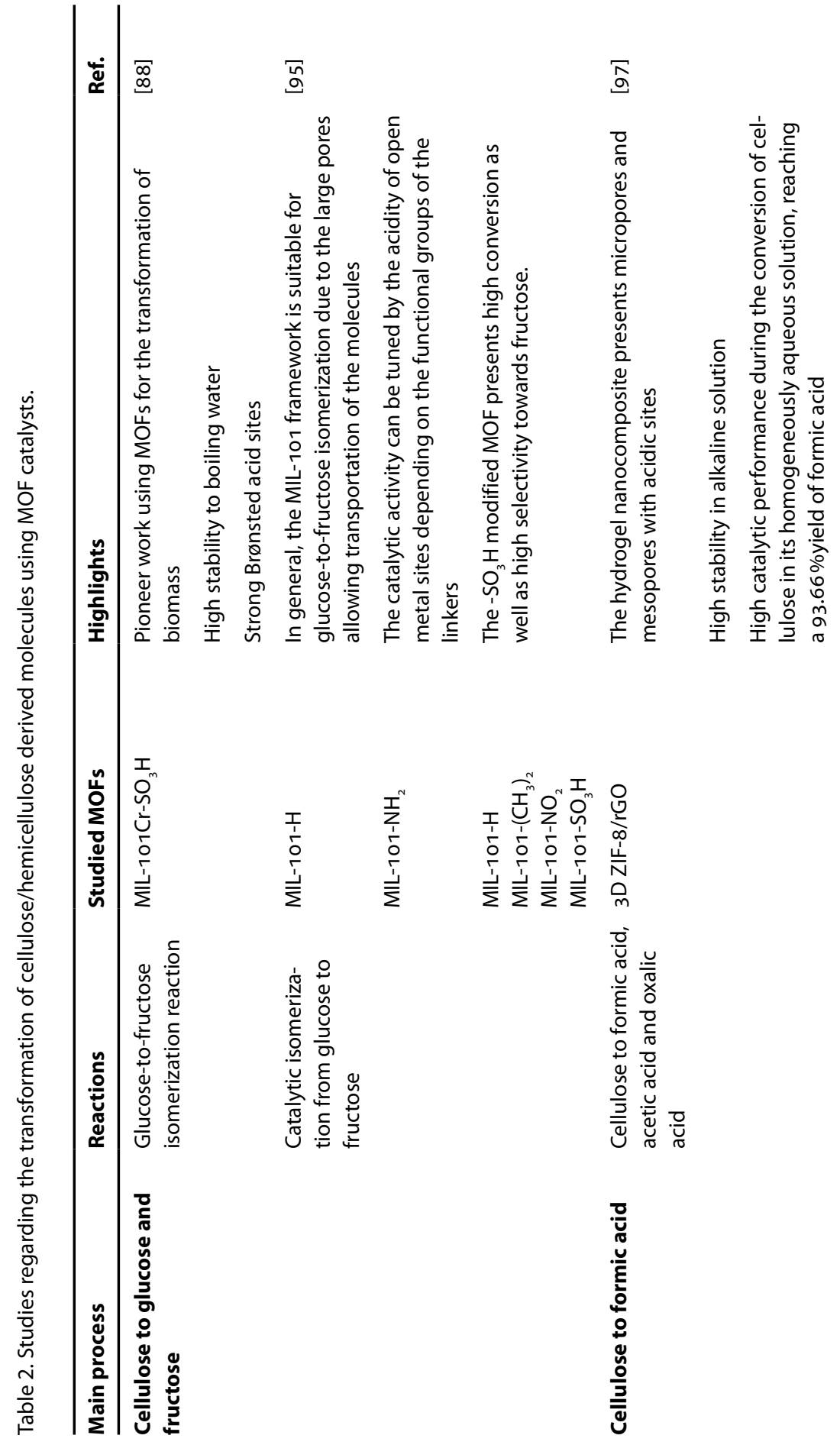


Б

$\stackrel{\circ}{\circ}$

$\stackrel{5}{5}$

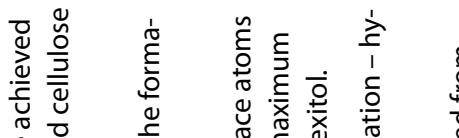

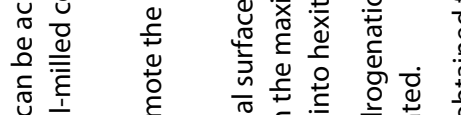

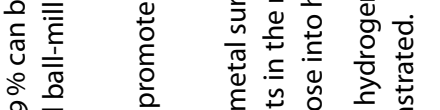

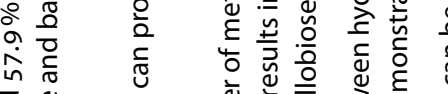

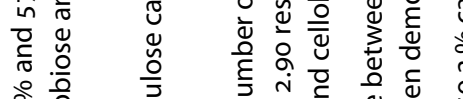

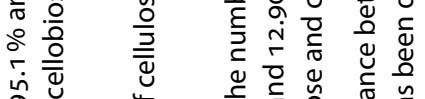

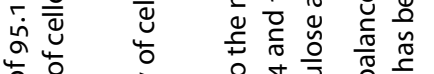

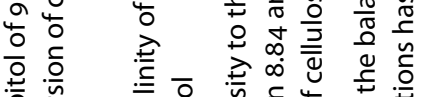

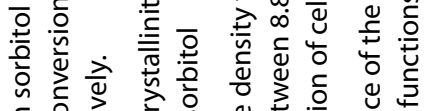

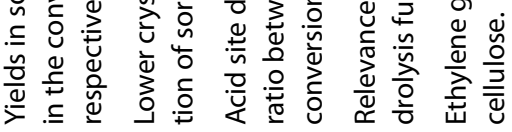

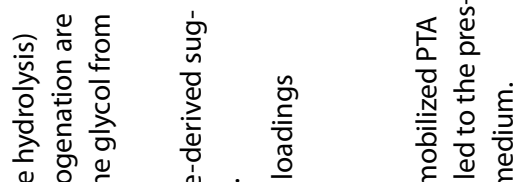

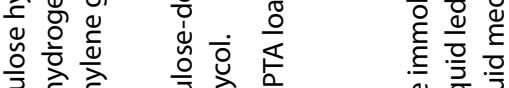

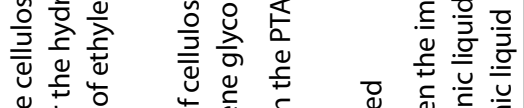

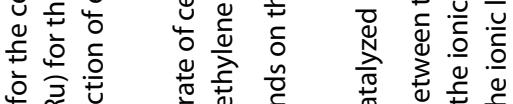

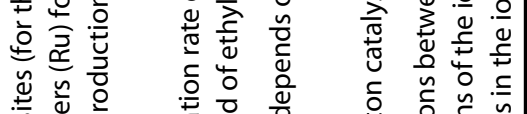

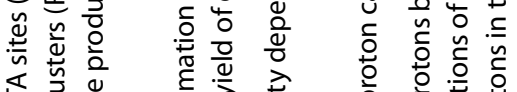

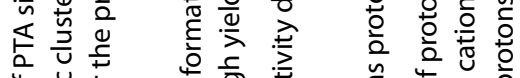

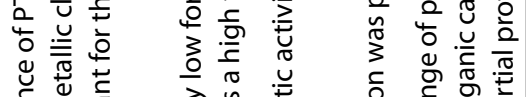

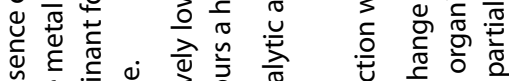

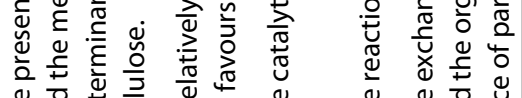

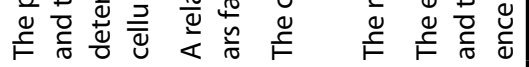

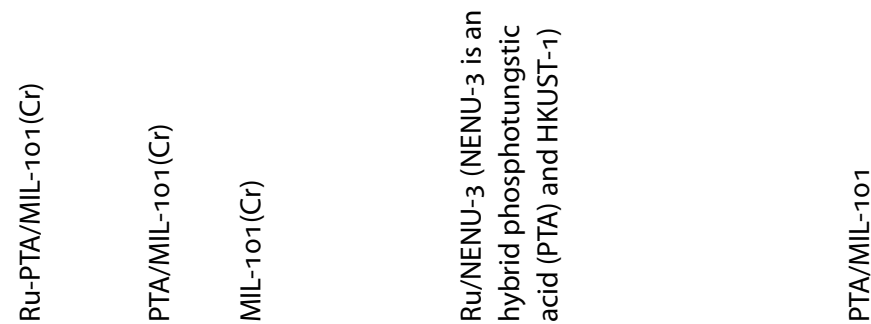

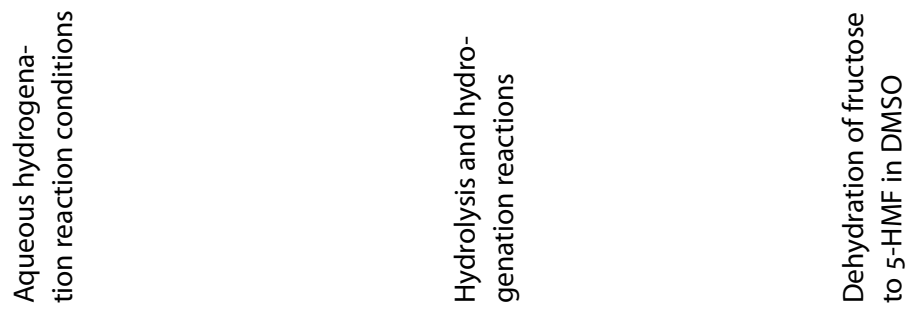

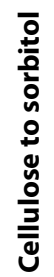

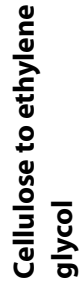

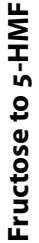




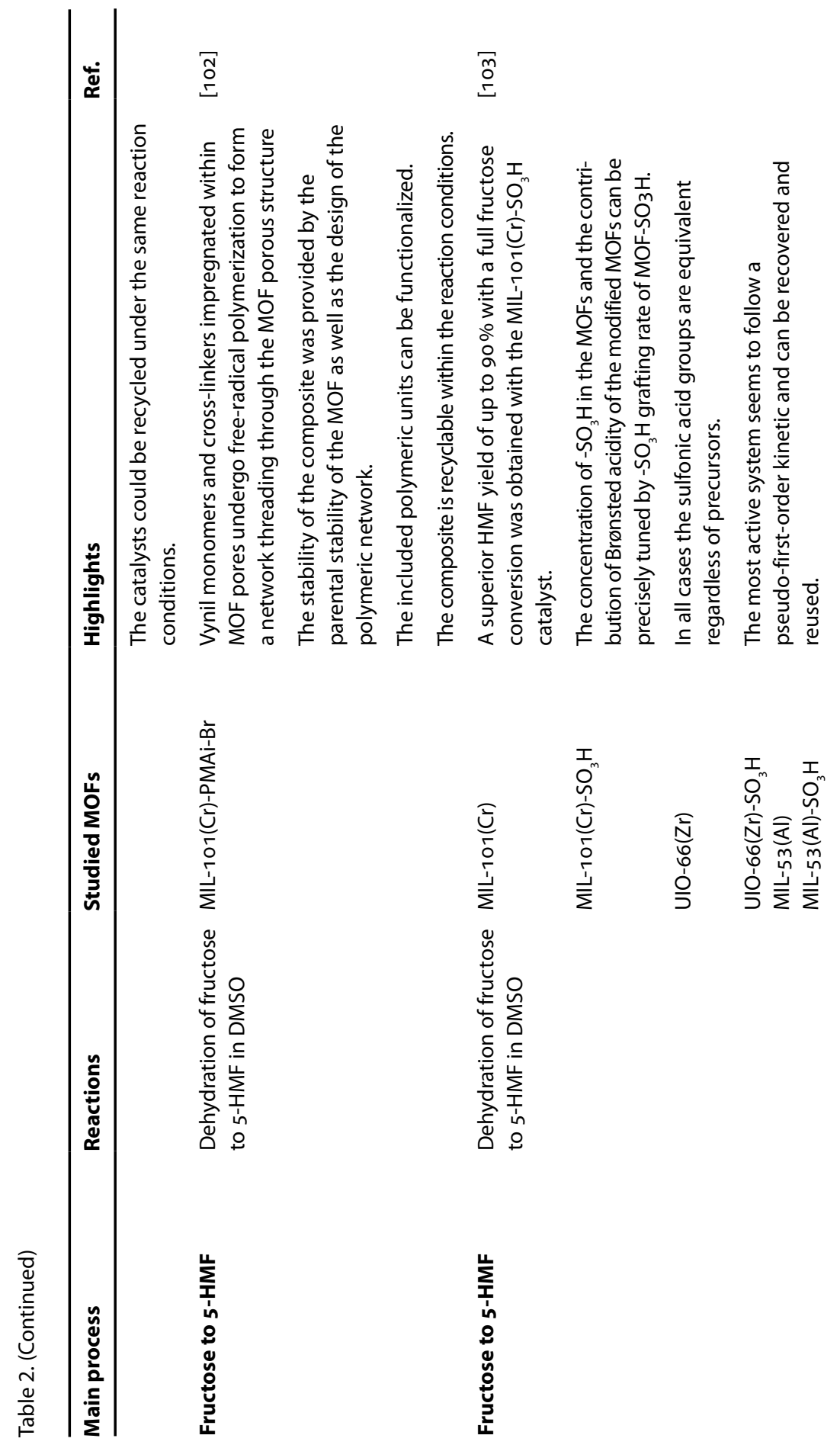


起 ن

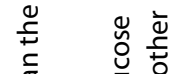

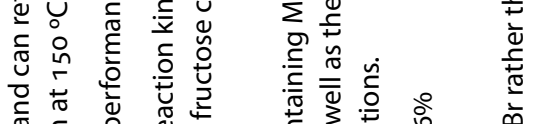

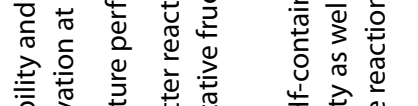

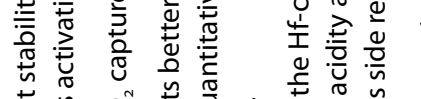

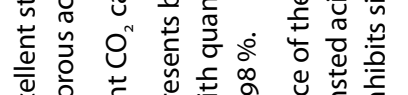

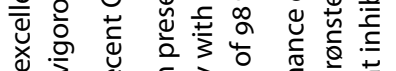

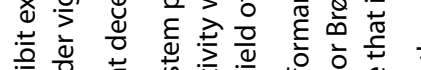

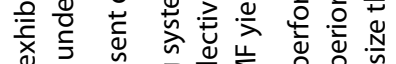

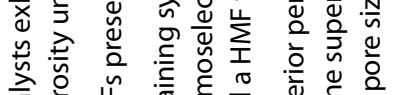

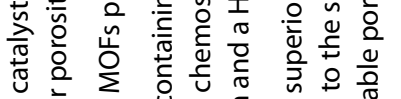

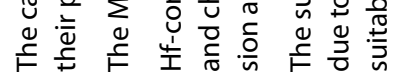

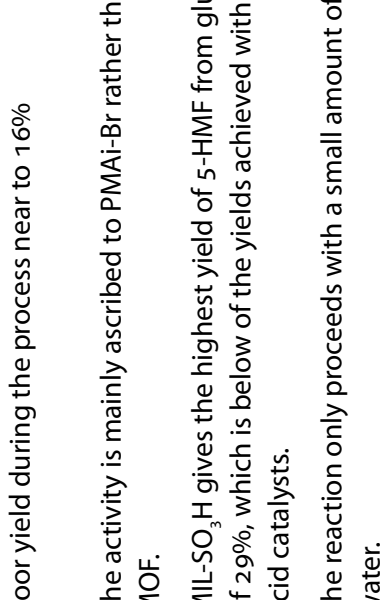

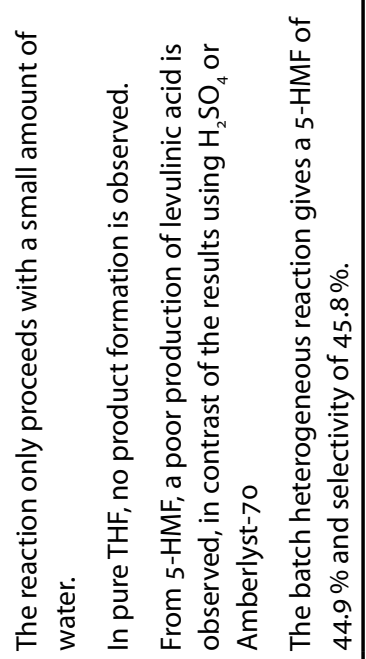

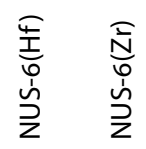

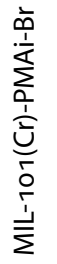

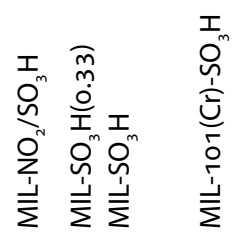

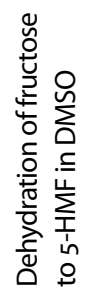

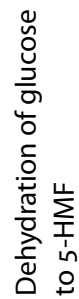

亡ั

$\stackrel{O_{i}^{n}}{\vec{\Sigma}}$

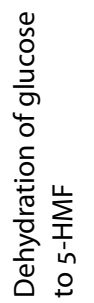

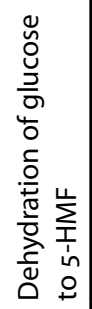

㭊

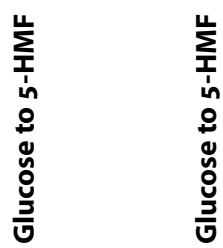

ind 


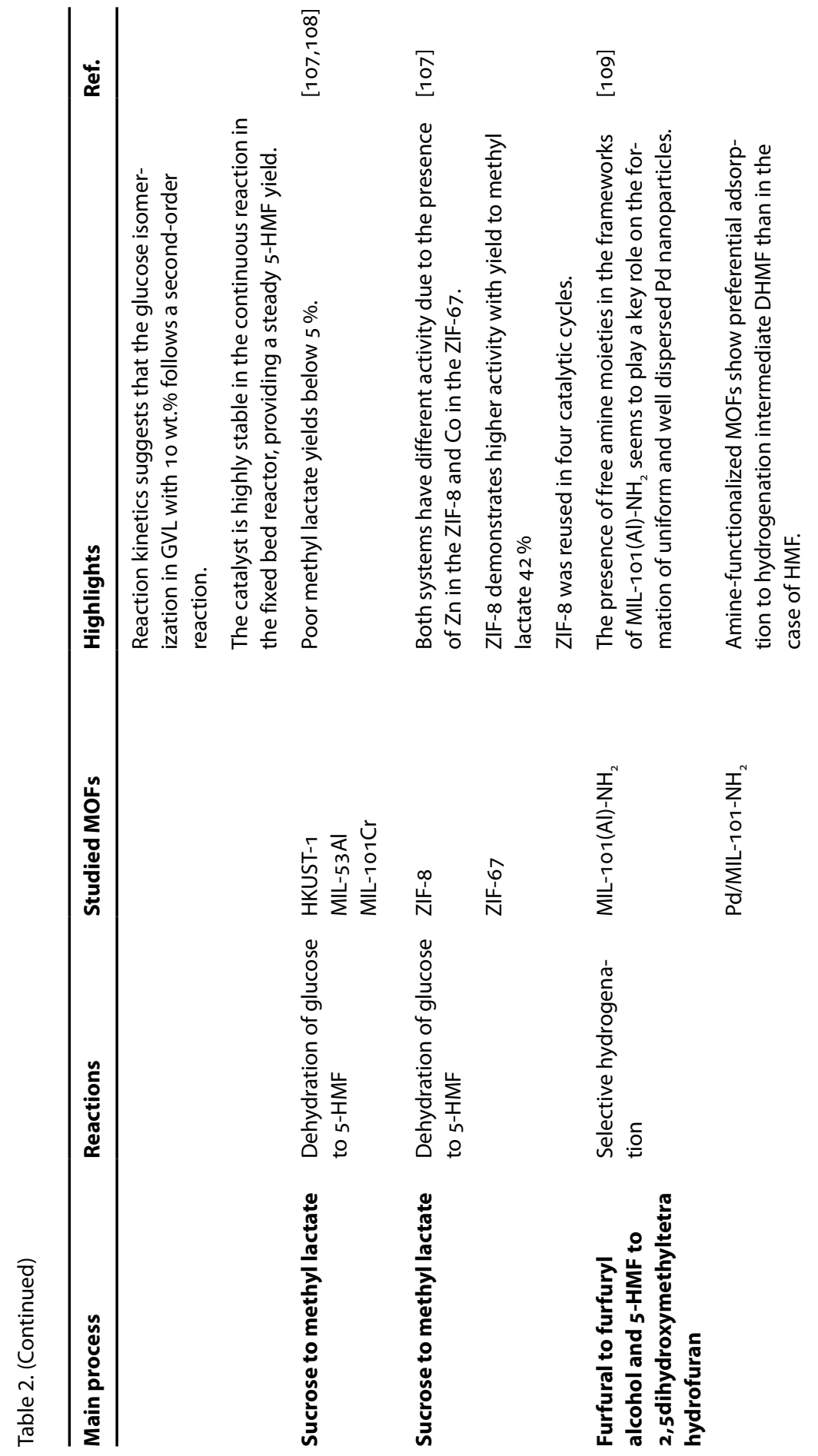


$\stackrel{ }{ }$

$\underset{\check{F}}{\check{E}}$

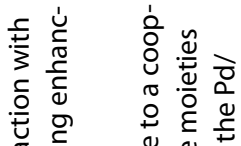

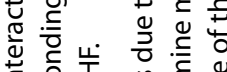

.

气 さ

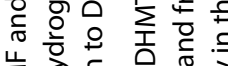

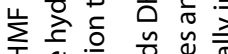

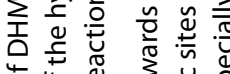

4

实记

ํำ 은

त䜦

ऽ

늘

등 흥 ㅎํㅇ

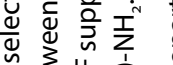

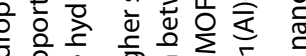

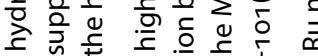

ॠ

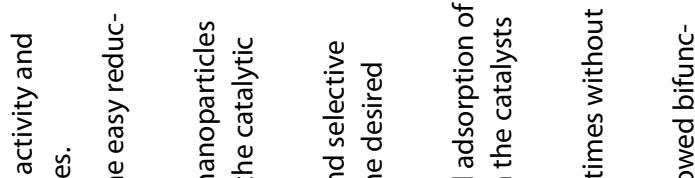

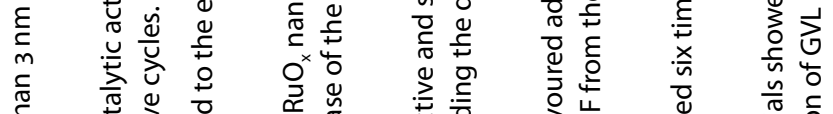

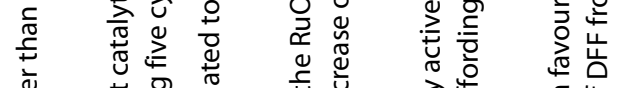

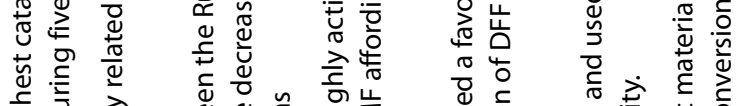

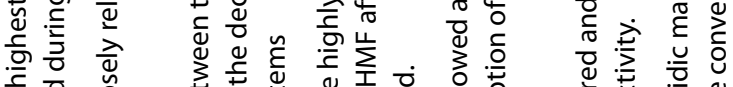

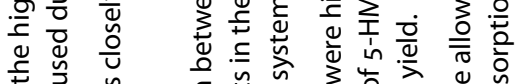

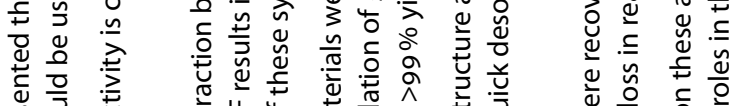

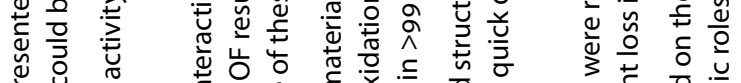

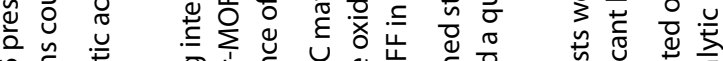

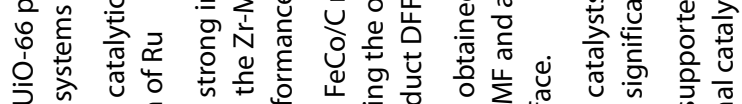
วथे

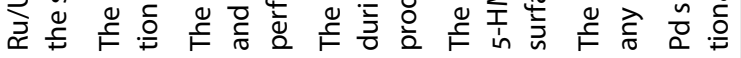
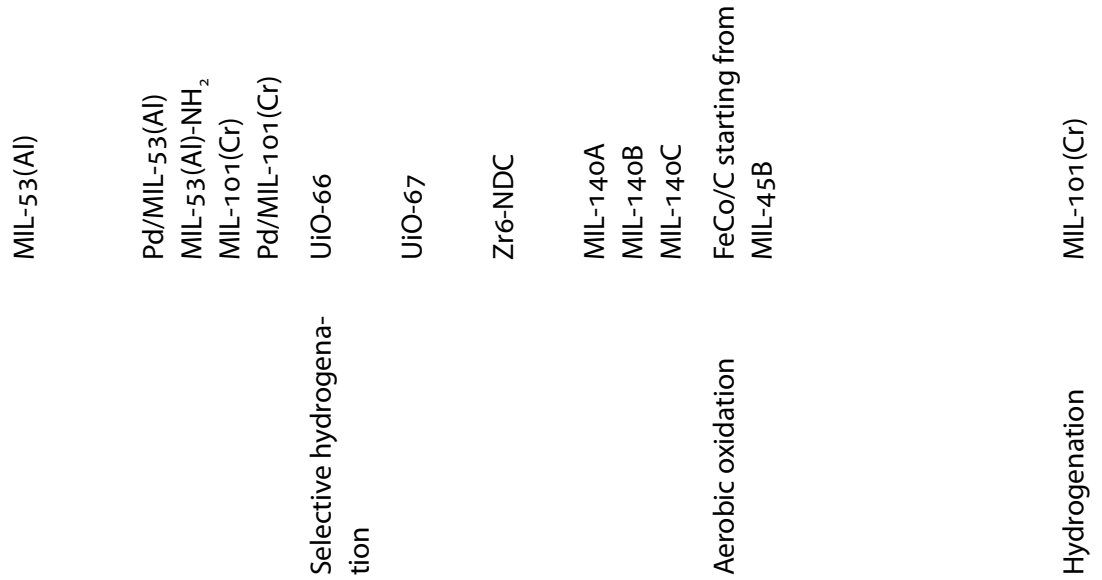

.0
$\frac{0}{0}$
$\frac{0}{0}$
$\frac{0}{x}$
.0
$\frac{0}{0}$
$\frac{0}{4}$
$\frac{8}{4}$
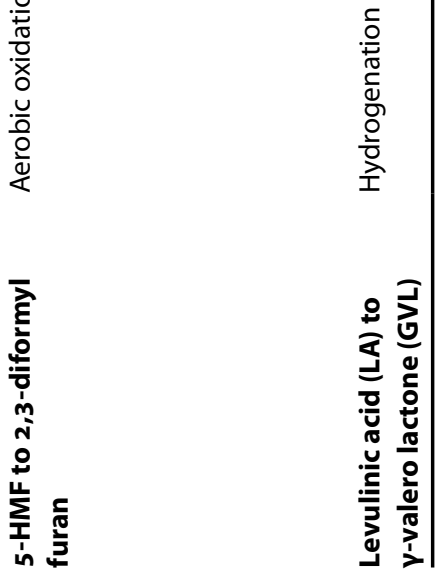


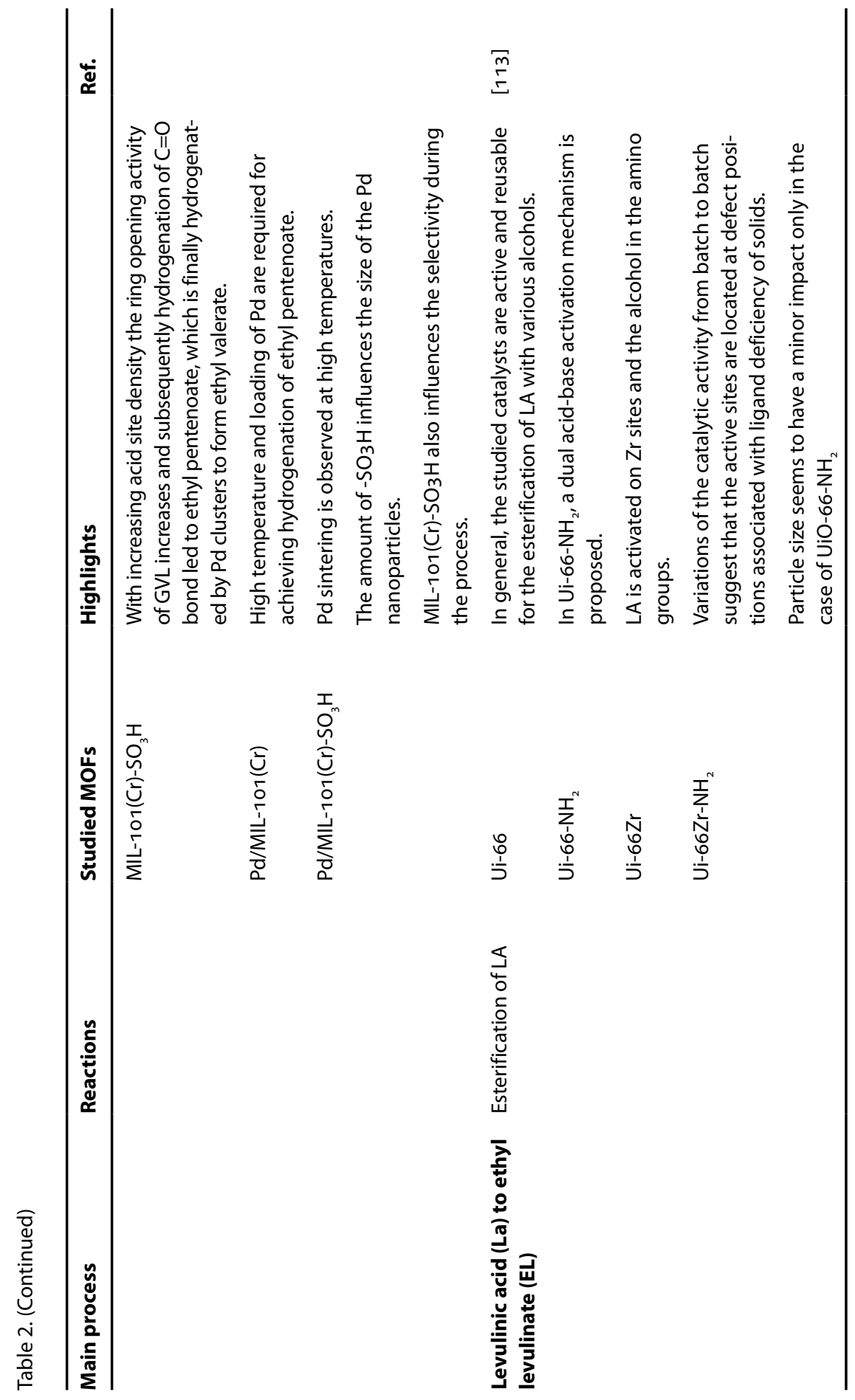


performance of the catalyst was attributed to the stability of the support, which maintained a high dispersion of the Pd nanoparticles. Additionally, the electronic activation of the reactants and the good dispersion of the catalyst in the water media were evidenced [114]. The same research team also reported the use of MOF catalysts based on the UiO-66 structure in the hydrodeoxygenation of vanillin [115]. The catalysts were prepared by introducing ultra-small Pd nanoparticles $\left(1.5^{-2.5} \mathrm{~nm}\right)$ into a highly porous and hydrothermally stable amine-functionalized UiO-66 $\left(\mathrm{NH}_{2}-\mathrm{UiO}-66\right)$. The stable and leaching-resistant dispersion of the Pd nanoparticles was attributed to the presence of free amine moieties in the framework of the catalyst. Consequently, the amine/Pd ratio should be optimized.

To the best of our knowledge, the most recent work devoted to the transformation of vanillin proposed the use of a hybrid support consisting of MOF crystals and partially reduced graphene oxide (PRGO) nanosheets to disperse metal nanoparticles. The Ce-based MOF was wrapped with thin PRGO nanolayers, and the obtained 5 wt.\% Pd/PRGO/Ce-MOF catalyst exhibited high catalytic activity in the tandem hydrogenation-deoxygenation reactions. Furthermore, it could be reused at least four times without any loss of activity or selectivity. The inclusion of PRGO seems to promote the selectivity of the process towards the production of 2-methoxy-4-methylphenol, which is an important phenol-type compound with high added value. In addition, PRGO provides stability and acidic sites that promote the hydrogenolysis reaction.

\section{Concluding remarks}

Zeolites and MOFs are very suitable materials to be used in reactions of biomass-to-chemicals. The chemical valorization of the lignocellulosic biomass involves a sequence of different catalytic processes, such as depolymerization, hydrolysis, hydrogenation, dehydration, isomerization, and oxidation reactions, among others. Thus, the high versatility of these materials, which extends to different porous structures (pore dimension and void volume), shape selectivity, number and nature of active sites (single or multiple), etc., makes them ideal for these applications by means of adjusting their structures to the desired reaction.

Literature reports have largely evidenced the strong capabilities of zeolites for the transformation of lignocellulosic biomass feedstocks, whereas the application of MOF-based catalysts goes almost unexplored. Few works on MOFs have been published so far, and only two MOF families (MIL-101 
and UiO-66) have demonstrated their stablilty under typical reaction conditions involving water and strongly acidic environments. Therefore, the design of novel MOFs is necessary, at the same time aiming to adapt the properties of the catalysts to the particular reaction under study. To this end, the tunability of Lewis and Brønsted acidity, as well as the nature of the open metal sites or the control of the hydrogen bonding interactions through the linkers are parameters amenable to modification. Furthermore, the hydrophilicity/hydrophobicity must be optimized to control the adsorption processes during the reactions [8o].

Apart from these considerations, the evolution of MOF-based catalysts for lignocellulosic biomass transformation must follow the principles of green chemistry [116]. One of these principles is the efficient utilization of raw materials. Thus, MOF catalysts need to be designed for the deconstruction of residual lignocellulosic biomass, which avoids competing with the food supply. However, this is a challenging task, since the processing of real residual biomass presents a huge complexity, including the presence of strongly deactivating species, such as sulphur- and nitrogen-containing compounds. Despite this, the success in using MOFs for this purpose would contribute both to the remediation of biomass waste and to the decreasing of the $\mathrm{CO}_{2}$ footprint as bio-derived fuels and fine chemicals would come from renewable carbon sources. Another approach that would improve the efficient use of resources would be the use of molecules derived from other transformations of lignocellulosic biomass in a biorefinery. This would also contribute to the decrease of $\mathrm{CO}_{2}$ emissions and would bring economic and environmental benefits.

\section{Acknowledgments}

The authors thank the support from the Spanish Ministerio de Economía y Competitividad (MINECO) (ENE2O15-66975-C3-2-R and ENE2013-4788o$\mathrm{C}_{3}-2-\mathrm{R}$ ) co-financed by FEDER funds from the European Union. Financial support from the Junta de Andalucía to the Surface Chemistry and Catalysis research group (TEP106) is specifically acknowledged.

\section{References}

[1] Field, C.B., Behrenfeld, M.J., Randerson, J.T., Falkowski, P. Science 1998, 281, 237.

[2] Huber, G.W., Iborra, S., Corma, A. Chem. Rev. 2006, 106, 4044.

[3] Dodds, D.R., Gross, R.A. Science 2007, 318, $125^{0 .}$ 
[4] Baily, M., Enari, T.M., Linko, M., Halliwell, G. In SITRA Symposium on Enzymatic Hydrolysis of Cellulose, Finland, 1975.

[5] Fan, L.T., Gharpuray, M.M., Lee, Y.H. Cellulose Hydrolysis, Springer, 1987.

[6] Devendra, L.P., Kumar, K.M., Pandey, A. Biores. Technol. 2016, 213, 350.

[7] Serrano-Ruiz, J.C., Luque, R., Sepulveda-Escribano, A. Chem. Soc. Rev. 2011, 40, 5266.

[8] Lin, H., Strull, J., Liu, Y., Karmiol, Z., Plank, K., Miller, G., Guo, Z., Yang, L. Energy J. Environ. Sci. 2012, 5, 9773.

[9] Nowakowski, D.J., Bridgwater, A.V., Elliott, D.C., Meier, D., de Wild, P.J.J. Anal. Appl. Pyrolysis 2010, 88, 53 .

[10] Liu, C., Wang, H., Karim, A.M., Sun, J., Wang, Y. Chem. Soc. Rev. 2014, 43, 7594.

[11] Zakzeski, J., Bruijnincx, P.C.A., Jongerius, A.L., Weckhuysen, B.M. Chem. Rev. 2010, 110, 3552.

[12] Björkman, A. Sven. Papperstidn 1956, 59, 477.

[13] Shuai, L., Luterbacher, J. ChemSusChem 2016, 9, 133.

[14] Piqueras, C.M., Cabeza, A., Gallina, G., Cantero, D.A., Garcia-Serna, J., Cocero, M.J. Chem. Eng.J. 2017, 308, 110.

[15] Corma, A., Iborra, S., Velty, A. Chem. Rev. 2007, 107, 2411.

[16] Zhang, X., Wilson, K., Lee, A.F. Chem. Rev. 2016, 116, 12328.

[17] Climent, M.J., Corma, A., Iborra, S. Zeolites and Catalysis: Synthesis, Reactions and Applications, Wiley-VCH, 2010.

[18] Dapsens, P.Y., Mondelli, C., Perez-Ramirez, J. ACS Catal. 2012, 2, 1487.

[19] Ennaert, T., Van Aelst, J., Dijkmans, J., De Clercq, R., Schutyser, W., Dusselier, M., Verboekend, D., Sels, B.F. Chem. Soc. Rev. 2016, 45, 584.

[20] Li, H., Yang, S., Riisager, A., Pandey, A., Sangwan, R.S., Saravanamurugan, S., Luque, R. Green Chem. 2016, 18, 5701.

[21] Corma, A., Nemeth, L.T., Renz, M., Valencia, S. Nature 2001, 412, 423.

[22] Bhosale, S.H., Rao, M.B., Deshpande, V.V. Microbiol. Mol. Biol. Rev. 1996, 6o, 280.

[23] Moreau, C., Durand, R., Roux, A., Tichit, D. Appl. Catal., A 2000, 193, 257.

[24] Moliner, M., Roman-Leshkov, Y., Davis, M.E. PNAS 2010, 107, 6164.

[25] Roman-Leshkov, Y., Moliner, M., Labinger, J.A., Davis, M.E. Angew. Chem. Int. Ed. 2010, 49, 8954.

[26] Gunther, W.R., Wang, Y., Ji, Y., Michaelis, V.K., Hunt, S.T., Griffin, R.G., Roman-Leshkov, Y. Nat. Commun. 2012, 3.

[27] van der Graaff, W.N.P., Tempelman, C.H.L., Li, G., Mezari, B., Kosinov, N., Pidko, E.A., Hensen, E.J.M. ChemSusChem 2016, 9, 3145 .

[28] Lew, C.M., Rajabbeigi, N., Tsapatsis, M. Micropor. Mesopor. Mater. 2012, 153, 55.

[29] Kobayashi, H., Komanoya, T., Guha, S.K., Hara, K., Fukuoka, A. Appl. Catal., A 2011, 409, 13.

[30] Huber, G.W., Chheda, J.N., Barrett, C.J., Dumesic, J.A. Science 2005, 308, 1446.

[31] Deng, W., Tan, X., Fang, W., Zhang, Q., Wang, Y. Catal. Lett. 2009, 133, 167.

[32] Negoi, A., Triantafyllidis, K., Parvulescu, V.I., Coman, S.M. Catal. Today 2014, 223, 122.

[33] Ennaert, T., Geboers, J., Gobechiya, E., Courtin, C.M., Kurttepeli, M., Houthoofd, K., Kirschhock, C.E.A., Magusin, P.C.M.M., Bals, S., Jacobs, P.A., Sels, B.F. ACS Catal. 2015, 5, 754.

[34] Bozell, J.J., Petersen, G.R. Green Chem. 2010, 12, 539.

[35] Teong, S.P., Yi, G., Zhang, Y. Green Chem. 2014, 16, 2015.

[36] Moreau, C., Durand, R., Pourcheron, C., Razigade, S. Ind. Crops Prod. 1994, 3, 85.

[37] Moreau, C., Durand, R., Peyron, D., Duhamet, J., Rivalier, P. Ind. Crops Prod. 1998, 7, 95.

[38] Kim, S.B., You, S.J., Kim, Y.T., Lee, S., Lee, H., Park, K., Park, E.D. Korean J. Chem. Eng. 2011, 28,710 .

[39] Roman-Leshkov, Y., Chheda, J.N., Dumesic, J.A. Science 2006, 312, 1933.

[40] Choudhary, V., Pinar, A.B., Sandler, S.I., Vlachos, D.G., Lobo, R.F. ACS Catal. 2011, 1, 1724.

[41] Yang, G., Pidko, E.A., Hensen, E.J.M. ChemSusChem 2013, 6, 1688. 
[42] Tan, M., Zhao, L., Zhang, Y. Biomass Bioenergy 2011, 35, 1367.

[43] Guo, J., Zhu, S., Cen, Y., Qin, Z., Wang, J., Fan, W. Appl. Catal. B 2017, 200, 611.

[44] Arias, K.S., Climent, M.J., Corma, A., Iborra, S. ACS Sustain. Chem. Eng. 2016, 4, 6152.

[45] Yan, K., Jarvis, C., Gu, J., Yan, Y. Renew. Sustain. Energy Rev. 2015, 51, 986.

[46] Chen, H., Yu, B., Jin, S. Biores. Technol. 2011, 102, 3568.

[47] Guerbuez, E.I., Wettstein, S.G., Dumesic, J.A. ChemSusChem 2012, 5, 383.

[48] Ya'aini, N., Amin, N.A.S., Asmadi, M. Biores. Technol. 2012, 116, 58.

[49] Ya'aini, N., Amin, N.A.S., Endud, S. Micropor. Mesopor. Mater. 2013, 171, 14.

[50] Fernandes, D.R., Rocha, A.S., Mai, E.F., Mota, C.J.A., Teixeira da Silva, V. Appl. Catal., A 2012, 425-426, 199.

[51] Saravanamurugan, S., Riisager, A. Catal. Commun. 2012, 17, 71.

[52] Qi, L., Horvath, I.T. ACS Catal. 2012, 2, 2247.

[53] Yepez, A., De, S., Salud Climent, M., Romero, A.A., Luque, R. Appl. Sci. 2015, 5, 532.

[54] Sheldon, R.A. Stud. Surf. Sci. Catal. 1991, 59, 33.

[55] Velarde, A.M., Bartl, P., Nießen, T.E.W., Hoelderich, W.F.J.J. Mol. Catal. A Chem. 2000, 157, 225.

[56] Dusselier, M., Van Wouwe, P., Dewaele, A., Makshina, E., Sels, B.F. Energy Environ. Sci. 2013, 6,1415 .

[57] Maki-Arvela, P., Simakova, I.L., Salmi, T., Murzin, D.Y. Chem. Rev. 2014, 114, 1909.

[58] Holm, M.S., Saravanamurugan, S., Taarning, E. Science 2010, 328, 602.

[59] Holm, M.S., Pagan-Torres, Y.J., Saravanamurugan, S., Riisager, A., Dumesic, J.A., Taarning, E. Green Chem. 2012, 14, 702.

[6o] Li, L., Stroobants, C., Lin, K., Jacobs, P.A., Sels, B.F., Pescarmona, P.P. Green Chem. 2011, 13,1175 .

[61] de Clippel, F., Dusselier, M., Van Rompaey, R., Vanelderen, P., Dijkmans, J., Makshina, E., Giebeler, L., Oswald, S., Baron, G.V., Denayer, J.F.M., Pescarmona, P.P., Jacobs, P.A., Sels, B.F. J. Am. Chem. Soc. 2012, 134, 10089 .

[62] Dong, W., Shen, Z., Peng, B., Gu, M., Zhou, X., Xiang, B., Zhang, Y. Sci. Rep. 2016, 6, 26713.

[63] Taarning, E., Saravanamurugan, S., Holm, M.S., Xiong, J., West, R.M., Christensen, C.H. ChemSusChem 2009, 2, 625 .

[64] West, R.M., Holm, M.S., Saravanamurugan, S., Xiong, J., Beversdorf, Z., Taarning, E., Christensen, C.H.J. Catal. 2010, 269, 122.

[65] Shen, W., Tompsett, G.A., Hammond, K.D., Xing, R., Dogan, F., Grey, C.P., Conner Jr, W.C., Auerbach, S.M., Huber, G.W. Appl. Catal., A 2011, 392, 57.

[66] Kikhtyanin, O., Kelbichová, V., Vitvarová, D., Kubů, M., Kubička, D. Catal. Today 2014, 227,154 .

[67] Kikhtyanin, O., Chlubna, P., Jindrova, T., Kubicka, D. Dalton Trans. 2014, 43, 10628.

[68] Kubička, D., Kikhtyanin, O. Catal. Today 2015, 243, 10.

[69] Kubicka, D., Kubickova, I., Cejka, J. Catal. Rev. Sci. Eng. 2013, 55, 1.

[70] Saiz-Jimenez, C., Deleeuw, J.W. Org. Geochem. 1986, 10, 869.

[71] Ma, Z., Custodis, V., Hemberger, P., Baehrle, C., Vogel, F., Jeschke, G., van Bokhoven, J.A. Chimia 2015, 69, 597 .

[72] Ma, Z., Troussard, E., van Bokhoven, J.A. Appl. Catal., A 2012, 423-424, 130.

[73] Ma, Z., van Bokhoven, J.A. ChemCatChem 2012, 4, 2036.

[74] Ma, Z., Custodis, V., van Bokhoven, J.A. Catal. Sci. Technol. 2014, 4, 766.

[75] Gayubo, A.G., Valle, B., Aguayo, A.T., Olazar, M., Bilbao, J.J. Chem. Technol. Biotechnol. 2010, $85,132$.

[76] Hicks, J.C. J.J. Phys. Chem. Lett. 2011, 2, 2280.

[77] Gayubo, A.G., Aguayo, A.T., Atutxa, A., Prieto, R., Bilbao, J. Energy Fuels 2004, 18, 1640.

[78] Deng, S.M., Fan, M.H., Wang, T.J., Li, Q.X. Chinese J. Chem. Phys. 2014, 27, 361. 
[79] Dhakshinamoorthy, A., Alvaro, M., Corma, A., Garcia, H. Dalton Trans. 2011, 40, 6344.

[8o] Herbst, A., Janiak, C. Cryst. Eng. Comm. 2017.

[81] Kitagawa, S., Kitaura, R., Noro, S. Angew. Chem. Int. Ed. 2004, 43, 2334.

[82] Ferey, G. Chem. Soc. Rev. 2008, 37, 191.

[83] Bloch, E.D., Britt, D., Lee, C., Doonan, C.J., Uribe-Romo, F.J., Furukawa, H., Long, J.R., Yaghi, O.M.J. Am. Chem. Soc. 2010, 132, 14382.

[84] Deng, H., Doonan, C.J., Furukawa, H., Ferreira, R.B., Towne, J., Knobler, C.B., Wang, B., Yaghi, O.M. Science 2010, 327, 846.

[85] Volkringer, C., Cohen, S.M. Angew. Chem. Int. Ed. 2010, 49, 4644.

[86] Bernt, S., Guillerm, V., Serre, C., Stock, N. Chem.Commun. 2011, 47, 2838.

[87] Farrusseng, D., Aguado, S., Pinel, C. Angew.Chem. Int. Ed. 2009, 48, 7502.

[88] Akiyama, G., Matsuda, R., Sato, H., Takata, M., Kitagawa, S. Adv. Mater. 2011, 23, 3294.

[89] Furukawa, H., Cordova, K.E., O’Keeffe, M., Yaghi, O.M. Science 2013, 341, 1230444.

[9o] Qadir, N.U., Said, S.A.M., Bahaidarah, H.M. Micropor. Mesopor. Mater. 2015, 201, 61.

[91] Burtch, N.C., Jasuja, H., Walton, K.S. Chem. Rev. 2014, 114, 10575.

[92] Kruger, J.S., Nikolakis, V., Vlachos, D.G. Curr. Opin. Chem. Eng. 2012, 1, 312.

[93] Gupta, K.M., Zhang, K., Jiang, J.W. Sci. Rep. 2015, 5.

[94] Yabushita, M., Li, P., Bernales, V., Kobayashi, H., Fukuoka, A., Gagliardi, L., Farha, O.K., Katz, A. Chem. Commun. 2016, 52, 7094.

[95] Akiyama, G., Matsuda, R., Sato, H., Kitagawa, S. Chem. Asian J. 2014, 9, 2772.

[96] Chen, J., Wang, S., Huang, J., Chen, L., Ma, L., Huang, X. ChemSusChem 2013, 6, 1545.

[97] Huang, P., Yan, L.F. Chinese J. Chem. Phys. 2016, 29, 742.

[98] Allendorf, M.D., Stavila, V., Ramakrishnan, P., Davis, R. Sandia Report 2014, SAND201418259, prod.sandia.gov/techlib/access.

[99] Stavila, V., Parthasarathi, R., Davi, R.W., El Gabaly, F., Sale, K.L., Simmons, B.A., Singh, S., Allendorf, M.D. ACS Catal. 2016, 6, 55 .

[100] Wang, S., Chen, J., Chen, L. Catal. Lett. 2014, 144, 1728.

[101] Zhang, Y., Degirmenci, V., Li, C., Hensen, E.J.M. ChemSusChem 2011, 4, 59.

[102] Bromberg, L., Su, X., Hatton, T.A. Chem. Mater. 2014, 26, 6257.

[103] Chen, J., Li, K., Chen, L., Liu, R., Huang, X., Ye, D. Green Chem. 2014, 16, 2490.

[104] Hu, Z., Peng, Y., Gao, Y., Qian, Y., Ying, S., Yuan, D., Horike, S., Ogiwara, N., Babarao, R., Wang, Y., Yan, N., Zhao, D. Chem. Mater. 2016, 28, 2659.

[105] Herbst, A., Janiak, C. New J. Chem. 2016, 40, 7958.

[106] Su, Y., Chang, G., Zhang, Z., Xing, H., Su, B., Yang, Q., Ren, Q., Yang, Y., Bao, Z. AIChEJ. 2016, 62, 4403.

[107] Park, K.S., Ni, Z., Cote, A.P., Choi, J.Y., Huang, R., Uribe-Romo, F.J., Chae, H.K., O’Keeffe, M., Yaghi, O.M. PNAS 2006, 103, 10186.

[108] Murillo, B., Zornoza, B., de la Iglesia, O., Tellez, C., Coronas, J.J. Catal. 2016, 334, 6 o.

[109] Chen, J., Liu, R., Guo, Y., Chen, L., Gao, H. ACS Catal. 2015, 5, 722.

[110] Yuan, Q., Zhang, D., van Haandel, L., Ye, F., Xue, T., Hensen, E.J.M., Guan, Y.J. Mol. Catal. A Chem. 2015, 406, 58 .

[111] Fang, R., Luque, R., Li, Y. Green Chem. 2016, 18, 3152.

[112] Zhang, D., Ye, F., Guan, Y., Wang, Y., Hensen, E.J.M. RSC Adv. 2014, 4, 39558.

[113] Cirujano, F.G., Corma, A., Llabres i Xamena, F.X. Chem. Eng. Sci. 2015, 124, 52.

[114] Zhang, F., Jin, Y., Fu, Y., Zhong, Y., Zhu, W., Ibrahim, A.A., El-Shall, M.S. J. Mater. Chem. A $2015,3,17008$.

[115] Zhang, F., Zheng, S., Xiao, Q., Zhong, Y., Zhu, W., Lin, A., El-Shall, M.S. Green Chem. 2016, 18, 2900.

[116] Sheldon, R.A. in Ionic Liquids in the Biorefinery Concept: Challenges and Perspectives, p 258, The Royal Society of Chemistry, 2016. 
